\title{
Properties of Layer 6 Pyramidal Neuron Apical Dendrites
}

\author{
Debora Ledergerber and Matthew Evan Larkum \\ Physiologisches Institut, Universität Bern, CH-3012 Bern, Switzerland
}

Layer 6 (L6) pyramidal neurons are the only neocortical pyramidal cell type whose apical dendrite terminates in layer 4 rather than layer 1. Like layer 5 pyramidal neurons, they participate in a feedback loop with the thalamus and project to other cortical areas. Despite their unique location in the cortical microcircuit, synaptic integration in dendrites of L6 neurons has never been investigated. Given that all other neocortical pyramidal neurons perform active integration of synaptic inputs via local dendritic spike generation, we were interested to establish the apical dendritic properties of L6 pyramidal neurons. We measured active and passive properties of the apical dendrites of L6 pyramidal neurons in the somatosensory region of rat cortical slices using dual patch-clamp recordings from somata and dendrites and calcium imaging. We found that L6 pyramidal neurons share many fundamental dendritic properties with other neocortical pyramidal neurons, including the generation of local dendritic spikes under the control of dendritic inhibition, voltage-dependent support of backpropagating action potentials, timing-dependent dendritic integration, distally located $I_{\mathrm{h}}$ channels, frequency-dependent $\mathrm{Ca}^{2+}$ spike activation, and NMDA spike electrogenesis in the distal apical dendrite. The results suggest that L6 pyramidal neurons integrate synaptic inputs in layer 4 similar to the way other neocortical pyramidal neurons integrate input to layer 1. Thus, L6 pyramidal neurons can perform a similar associational task operating on inputs arriving at the granular and subgranular layers.

\section{Introduction}

Neocortical layer (L) 6 contains a diverse population of pyramidal neurons which have dendritic properties yet to be explored. A subset of these pyramidal cells sends projections to the thalamus (Bourassa et al., 1995; Diamond and Jones, 1995), innervating both primary and higher order thalamic nuclei (Sherman and Guillery, 2002; Reichova and Sherman, 2004). Another group of L6 pyramidal neurons provide projections to other cortical areas (Zhang and Deschènes, 1997) and both populations provide recurrent input to the column (Mercer et al., 2005). One of the critical distinctions between most L6 pyramidal neurons and all other neocortical pyramidal neurons is that their apical dendrite does not ramify in L1. Instead, the apical dendrite usually projects to upper L5 or into L4 with comparatively few and shorter tuft branches (Ferrer et al., 1986). Apart from the well described thalamic input providing both excitation and evoking disynaptic inhibition in L4 (Bruno and Simons, 2002; Swadlow, 2002; Cruikshank et al., 2007, 2010), the distal apical shaft and tuft dendrites of L6 pyramidal neurons also overlap with the recurrent projection from collateral axons of L6 corticothalamic pyramidal neurons (Zhang and Deschènes, 1998). This means that the input to the distal apical dendrites of L6 pyramidal neurons is different from all other neocortical pyramidal neurons. Predicting their output behavior and influence on the thalamus and

\footnotetext{
Received May 3, 2010; revised June 18, 2010; accepted July 26, 2010.

This work was supported by the Swiss National Science Foundation (Grant PP00A-102721/1) and SystemsX.ch (NEUROCHOICE). We thank Kay Thurley, Brice Bathellier, and Arnd Roth for helpful discussion and assistance with experiments and modeling; Kathrin Fischer for Neurolucida reconstructions; and Paul Adams, Hans-Rudolf Lüscher, Lucy M. Palmer, and Rogier Min for their helpful comments on the manuscript. We also thank Daniel Morris for visualization software.

Correspondence should be addressed to Matthew E. Larkum, Institute of Physiology, University of Bern, Bühlplatz 5, CH-3012 Bern, Switzerland. E-mail: matthew.larkum@gmail.com. DOI:10.1523/JNEUROSCI.2254-10.2010

Copyright $\odot 2010$ the authors $\quad$ 0270-6474/10/3013031-14\$15.00/0
}

other cortical areas is only possible with a detailed understanding of their response to distal apical input.

The properties of the apical dendrites of pyramidal neurons from different layers and different cortical areas, including the hippocampus, have been extensively explored. This body of work has shown that apical dendrites are typically endowed with a large complement of voltage-gated ion channels, which influence the integrative process and signal propagation within the dendritic tree (Johnston et al., 1996; Häusser et al., 2000; Berger et al., 2001; London and Häusser, 2005; Spruston, 2008). All pyramidal neurons so far investigated have displayed active propagation of action potentials (APs), from the soma along the apical dendrite supported by voltage-gated dendritic $\mathrm{Na}^{+}$channels (Spruston et al., 1995; Stuart et al., 1997; Waters et al., 2003), modulated by dendritic $\mathrm{K}^{+}$channels (Bekkers, 2000; Johnston et al., 2000; Korngreen and Sakmann, 2000; Schaefer et al., 2007), and accompanied by influx of $\mathrm{Ca}^{2+}$ ions (Markram et al., 1995; Larkum et al., 1999a; Barth et al., 2008). Another prominent feature of pyramidal neurons is the ability of the apical dendrite to generate local spikes with voltage-gated $\mathrm{Na}^{+}$and $\mathrm{Ca}^{2+}$ channels (Kim and Connors, 1993; Schiller et al., 1997; Golding et al., 2002; Gasparini et al., 2004) as well as NMDA receptor channels (Schiller et al., 2000; Larkum et al., 2009). In neocortical L5 neurons, these regenerative properties can determine the pattern of axonal output spiking (Larkum and Zhu, 2002) and are also controlled by local dendritic inhibition (Pérez-Garci et al., 2006). Furthermore, the interactions of spikes propagating within the dendritic tree greatly extend the computational power of these neurons (London and Häusser, 2005); however, none of these properties have yet been explored in L6 pyramidal neurons. Here, we investigate the properties of L6 pyramidal dendrites using direct patch-clamp recordings from somata and dendrites as well as calcium imaging in slices of rat somatosensory cortex. 

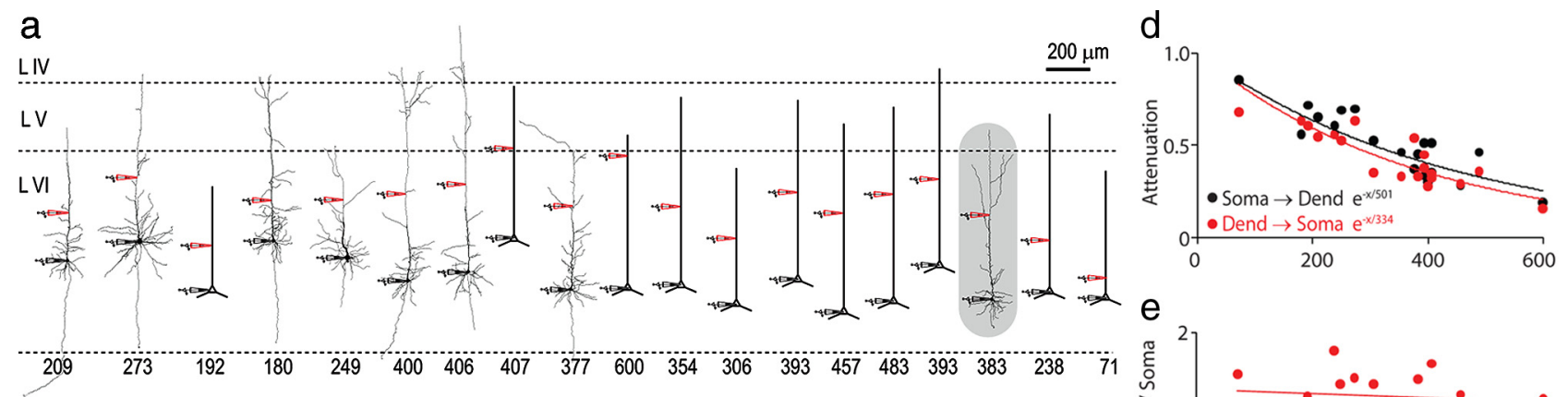

b1 b2

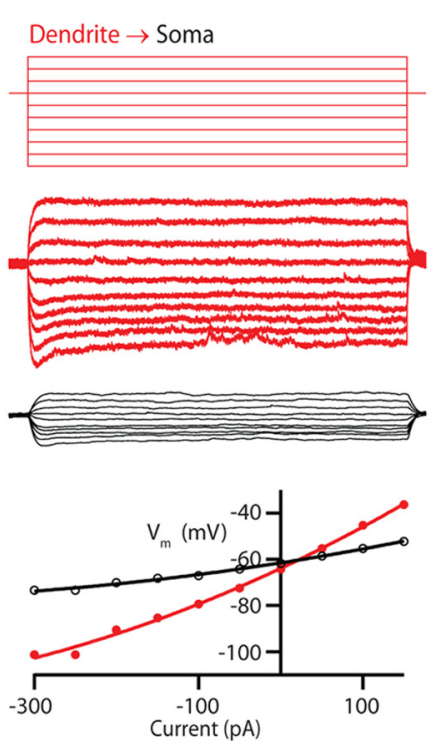

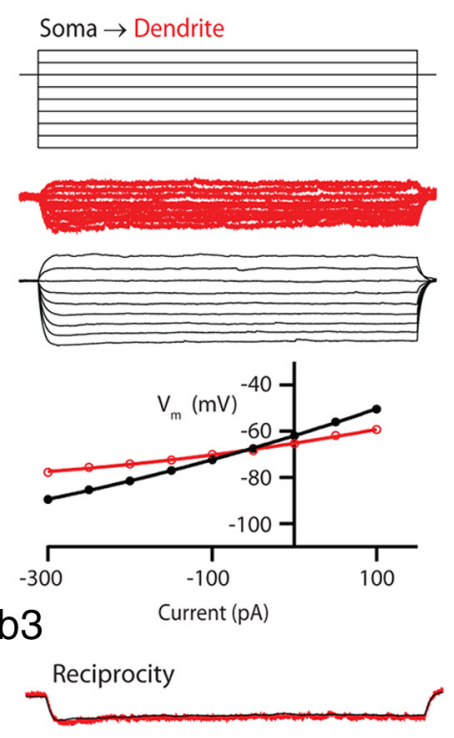
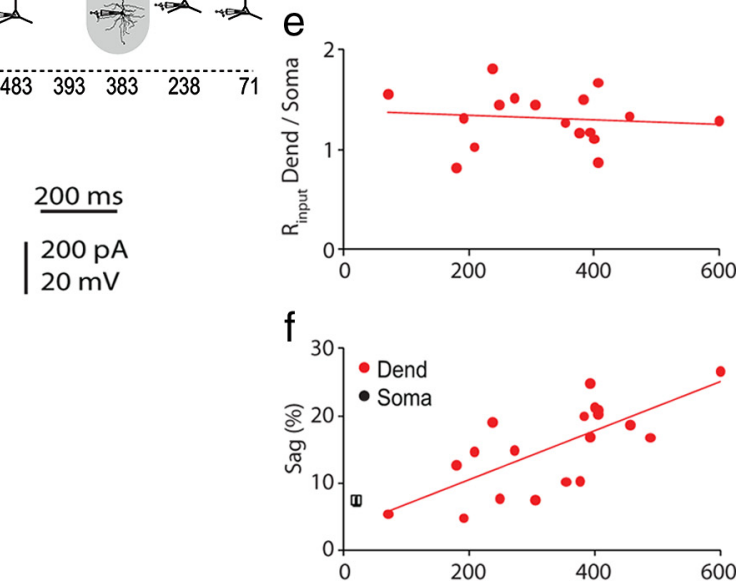

C

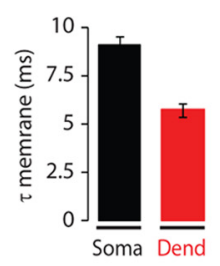

g

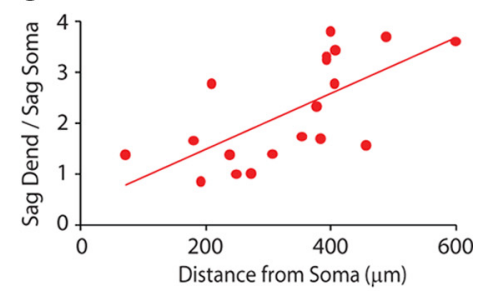

Figure 1. Passive steady-state properties of layer 6 (L6) pyramidal neurons. $\boldsymbol{a}$, L6 pyramidal neurons reconstructed from biocytin-filled neurons after the experiment or sketched from fluorescent-dye-filled neurons during the experiment (red electrodes, dendritic recording sites; black electrodes, somatic recordings). The number below each neuron indicates the distance of the dendritic electrode from the soma (in $\mu \mathrm{m}$ ). The neuron shaded in gray is the cell for which data are shown in $\boldsymbol{b}$. $\boldsymbol{b}, 0$ ne-second-step current injections (top) to the dendrite ( $\boldsymbol{b} \mathbf{1}$ ) and to the soma ( $\boldsymbol{b} 2$ ) and resulting voltage responses (middle, red traces, dendrite; black traces, soma). Bottom, The steady-state I-V relationships at dendrite and soma for both dendritic and somatic current injection. $\boldsymbol{b} 3$, Voltage recordings with current injection at the reciprocal site for both somatic and dendritic current injection. $\boldsymbol{c}$, Local membrane time constant ( $\tau$ membrane) [black, soma, $9.1 \mathrm{~ms}$; red, dendrite (Dend), $5.7 \mathrm{~ms}$. $\boldsymbol{d}$, Steady-state voltage attenuation from soma to dendrite (black) and from dendrite to soma (red) for recordings from different cells at different distances along the apical dendrite. $\boldsymbol{e}$, Input resistance $\left(R_{\text {input }}\right)$ at the dendrite versus soma (red circles) as a function of distance from soma. $\boldsymbol{f}$, Sag at dendritic recording as a function of distance from soma. $\boldsymbol{g}$, Ratio of sag at the dendrite to the soma.

\section{Materials and Methods}

Slice preparation. Experiments were performed in somatosensory neocortical slices from postnatal day (P)28-35 Wistar rats $(n=26)$, using procedures described previously (Waters et al., 2003). Briefly, rats were decapitated and the brain was quickly removed into cold $\left(0-4^{\circ} \mathrm{C}\right)$, oxygenated physiological solution containing the following (in $\mathrm{mm}$ ): 125 $\mathrm{NaCl}, 2.5 \mathrm{KCl}, 1.25 \mathrm{NaH}_{2} \mathrm{PO}_{4}, 25 \mathrm{NaHCO}_{3}, 1 \mathrm{MgCl}_{2}, 2 \mathrm{CaCl}_{2}$, and 25 glucose, $\mathrm{pH}$ 7.4. Parasagittal slices, $300 \mu \mathrm{m}$ thick, were cut from the tissue block with a vibratome (Microm) and kept at $37^{\circ} \mathrm{C}$ for $30 \mathrm{~min}$ and then at room temperature until use.

Electrophysiology. All experiments were performed at $32.0 \pm 0.5^{\circ} \mathrm{C}$. Single L6 pyramidal neurons were identified using infrared Dodt gradient contrast or oblique illumination and a CCD camera (CoolSnap ES; Roper Scientific). Slices were perfused with the same extracellular solution mentioned above. Recording pipettes were filled with intracellular solution containing the following (in $\mathrm{mm}$ ): $130 \mathrm{~K}$-gluconate, $5 \mathrm{KCl}, 30$ HEPES, 10 phosphocreatine, 4 MgATP, 0.3 GTP, pH 7.3. In addition, the somatic pipette contained the following: 10-50 $\mu \mathrm{M}$ Alexa 594 (Invitrogen), $100 \mu \mathrm{M}$ Oregon Green BAPTA-1 (OGB-1; Invitrogen), and 0.2\% Biocytin (Sigma). Dual whole-cell voltage recordings were performed from the soma and dendrites (6-10 and 20-40 M $\Omega$ pipette resistances, respectively) using Axoclamp 2A (Molecular Devices) and Dagan BVC-
700A amplifiers (Dagan Corporation). We did not correct for the liquid junction potential, which was determined experimentally to be $-11 \mathrm{mV}$. Access resistance for the dendritic recordings was 15-90 MOhms on break-through. Data were acquired with an ITC-18 board (Instrutech) and custom software written for the Igor environment (Wavemetrics). After recordings, slices were fixed and stained as described previously (Schiller et al., 1997) for later reconstruction of the investigated neurons.

Histology. Cells were filled with biocytin during the recordings and preserved in $4 \%$ paraformaldehyde for up to 2 weeks before being developed and mounted on cover slides. Tissue sections were processed with the avidin-biotin-peroxidase method to reveal cell morphology. The dendritic morphology was reconstructed with the aid of a computerized reconstruction system (Neurolucida).

The end of the apical dendrite terminated abruptly in some neurons, without an obvious tuft as has been observed previously (Larkman and Mason, 1990; Zhang and Deschènes, 1997; Brumberg et al., 2003; Mercer et al., 2005; West et al., 2006; Kumar and Ohana, 2008). This was not an artifact due to damage during the slicing process. References in the text to "distal apical dendrite" apply to the distal portion of the apical dendrite and/or the tuft. "Distal" in this context was in the most distal half of the apical dendrite but was in many cases much closer to the dendritic end point. 
Table 1. Summary of passive properties in the soma and apical dendrite of $L 6$ pyramidal neurons

\begin{tabular}{lcc}
\hline & \multicolumn{1}{c}{ Soma } & \multicolumn{1}{c}{ Dendrite } \\
\hline Resting $V_{\mathrm{m}}(\mathrm{mV})$ & $-68.37 \pm 1.71$ & $-72.23 \pm 1.53$ \\
$R_{\text {in }}(\mathrm{M} \Omega)$ & $114.36 \pm 6.38^{*}$ & $153.86 \pm 8.83^{*}$ \\
$\tau(\mathrm{ms})$ & $9.09 \pm 0.46^{*}$ & $5.75 \pm 0.34^{*}$ \\
$C_{\mathrm{AR}}$ & $102.37 \pm 14.73^{*}$ & $97.82 \pm 13.77^{*}$ \\
Sag $(\%)$ & $7.48 \pm 0.71^{*}$ & $15.39 \pm 1.40^{*}$ \\
Reobase $(\mathrm{pA})$ & $184.21 \pm 12.90^{*}$ & $265.00 \pm 24.55^{*}$ \\
AP threshold $(\mathrm{mV})$ & $-46.26 \pm 1.57^{\dagger}$ & $-20.99 \pm 2.22^{*}$ \\
AP amplitude $(\mathrm{mV})$ & $88.86 \pm 2.00^{\dagger}$ & $47.69 \pm 5.51^{\dagger}$ \\
AP half width (ms) & $0.881 \pm 0.051^{\dagger}$ & $5.922 \pm 1.433^{\dagger}$ \\
Recording distance from soma $(\mu \mathrm{m})$ & 0 & $336 \pm 126$ \\
\hline
\end{tabular}

$60 \times$ objective. Calcium transients are reported as the mean change in OGB-1 fluorescence $(F(t))$ over a $1 \mathrm{~s}$ window normalized to the resting OGB fluorescence $\left(F_{0}\right)$,

$$
\frac{F(t)-F_{0}}{F_{0}}
$$

Data analysis. Data analysis was performed using Igor software (Wavemetrics) and Excel (Microsoft). Statistical tests were performed with Excel using, if not otherwise indicated, a paired, two-tailed Student's $t$ test.

The membrane time constant $\left(\tau_{\mathrm{m}}\right)$ was measured by fitting a double exponential equation to the voltage response to a long, negative current injection ( -200 to $-300 \mathrm{pA})$ and choosing the longer time constant.

Sag response was calculated with the equation:

${ }^{*}$, Value obtained with $1 \mathrm{~s}$ current injection; ${ }^{\dagger}$, value obtained with 2 ms current injection.

a1

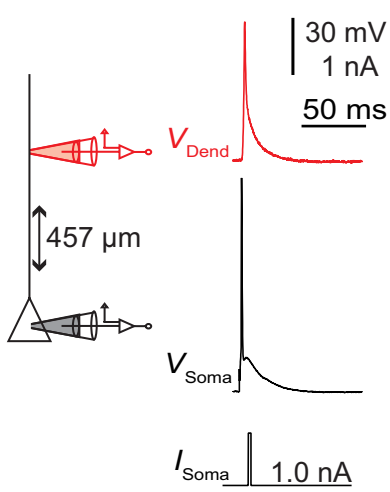

a2

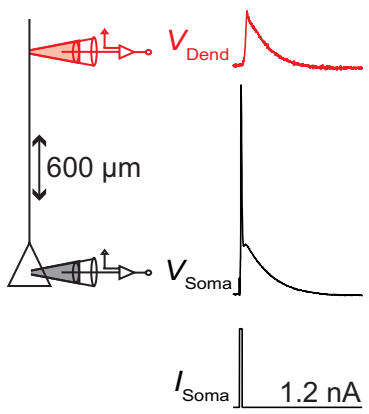

b

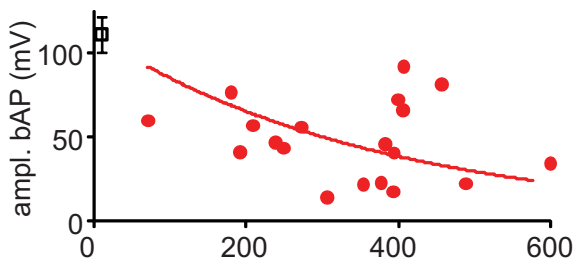

C

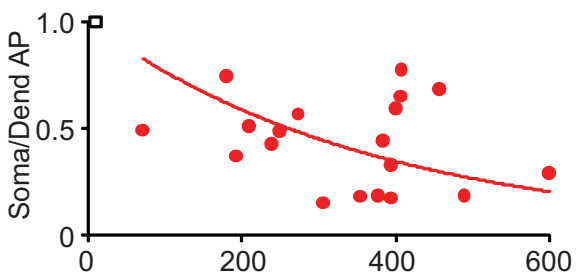

d

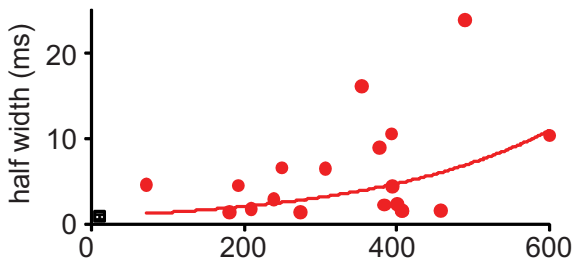

e

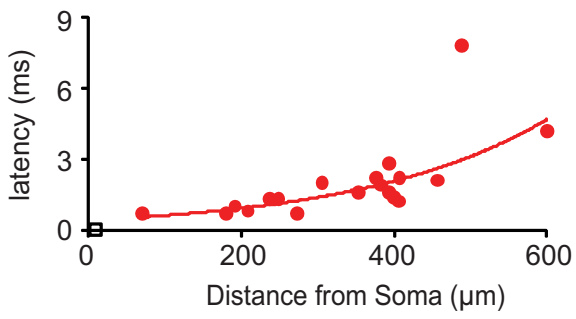

Figure 2. Backpropagation of single somatic APs. $\boldsymbol{a}$, Schematic diagram showing the experimental setup with the distance between the somatic (black) and the dendritic (red) electrode for different recording sites. A short ( $2 \mathrm{~ms}$ ) current injection near threshold (bottom trace, $I_{\text {soma }}$ ) evoked an AP at the soma (black trace) that propagated back into the dendrite (red trace). $\boldsymbol{b}$, Amplitude of single bAPs in the dendrite plotted as a function of distance from soma. c, Ratio of somatic AP to dendritic bAP amplitude as a function of distance from soma. $\boldsymbol{d}, \boldsymbol{e}$, Half-width ( $\boldsymbol{d}$ ) and latency $(\boldsymbol{e})$ of bAPs in the dendrite as a function of distance from soma.

Imaging. Dendritic recordings were made at least 20 min after establishing the somatic recording to allow intracellular spread of the dyes from the soma. Dendrites were targeted using combined twophoton excitation fluorescence microscopy with infrared (IR)scanning gradient contrast (Nevian and Sakmann, 2004) or an overlay of the separately acquired epifluorescence image with an obliquely illuminated IR image using custom software. We used a Leica TCS SP2 confocal scanner or an Olympus BX-51WI microscope with a

$$
\text { Sag }=\frac{\left(V_{\text {baseline }}-V_{\text {steady-state }}\right)}{V_{\text {baseline }}-V_{\text {min }}},
$$

using $V_{\mathrm{m}}$ recorded at baseline ( $\left.V_{\text {baseline }}\right)$, the minimum value reached soon after the beginning of the stimulus $\left(V_{\min }\right)$, and the steady-state value averaged between 400 and $900 \mathrm{~ms}$ after the beginning of the stimulus $\left(V_{\text {steady-state }}\right)$.

Following Waters and Helmchen (2006), we calculated the input resistance by fitting the following quadratic equation to the steady-state voltage deflection as a function of the responses to long-current injection:

$$
\Delta V=R_{\mathrm{N}, 0} \Delta I+C_{\mathrm{AR}} \Delta I^{2}
$$

where $R_{\mathrm{N}, 0}$ is the slope of the curve at $I=0$ (i.e., input resistance at resting membrane potential) and $C_{\mathrm{AR}}$ is the coefficient of anomalous rectification.

To estimate the occurrence of dendritic plateau potentials in the apical dendrite with long dendritic current injection, we determined the longest depolarization sustained at $20 \%$ or more above the baseline level (defined as the most hyperpolarized membrane potential during the dendritic current injection). This included the effects of backpropagating APs as well as their interplay with the dendritic depolarization.

Corticocortical versus corticothalamic neurons. L6 pyramidal neurons can be divided into two categories based on the projection of their axonal arborizations: corticothalamic (CT) and corticocortical (CC) projecting neurons (Zhang and Deschènes, 1997; Kumar and Ohana, 2008). In slice recordings, this distinction is often made with injection of retrograde tracers to the thalamus and/or cortex. Because of the low success rate for dendritic recordings per preparation, this approach was not feasible for this study. However, a previous study found that $\mathrm{CT}$ and $\mathrm{CC}$ neurons in young rats (P19-P22) are separable according to their electrophysiological properties (Kumar and Ohana, 2008); CT neurons have shorter time constants, AP half-widths, and AP latencies, and higher rheobase (i.e., the threshold for APs with long current injections at the soma) than CC neurons. Another striking difference found between CT and CC neurons in that study was the presence or absence of doublets or triplets of APs at the onset of a long current injection to the soma at twice rheobase. This last criterion (the onset spiking pattern at twice rheobase) was used to separate the cells into two groups (supplemental Fig. 1, available at www. 
jneurosci.org as supplemental material). We did not observe a dichotomy for any of the dendritic properties investigated. This suggests that there is no difference in dendritic properties of CC and CT projecting cells. On this basis, we decided to pool all the results concerning dendritic properties throughout the paper, but the segregated properties according to the above-mentioned classification are shown in supplemental Figure 1 (available at www.jneurosci.org as supplemental material).

\section{Results}

We investigated the dendritic properties of L6 neocortical pyramidal cells in young adult rats (P28-P35) using dual wholecell recordings from somata and dendrites. The cell bodies were located in upper L6a defined according to Zhang and Deschènes (1997) in the primary somatosensory cortex at a mean depth of $1524 \pm 95 \mu \mathrm{m}(1333-1680 \mu \mathrm{m} ; n=26)$ below the pia. The dendritic electrode was placed at various distances between 71 and $600 \mu \mathrm{m}$ from soma (Fig. 1a, red electrodes).

\section{Passive properties of L6 pyramidal apical dendrites}

To investigate the passive cable properties of L6 apical dendrites, we injected prolonged stepwise currents (500-1000 ms) at either the dendritic or the somatic electrodes (Fig. 1b). The steady-state voltage deflection showed anomalous rectification (Fig. 1b, bottom) (Connors et al., 1982), which we quantified according to Waters and Helmchen (2006) using a coefficient of anomalous rectification $\left(C_{\mathrm{AR}}=102.4 \pm 66.7\right.$ for soma and $C_{\mathrm{AR}}=$ $97.8 \pm 59.7$ for dendrite, $n=17$ ) (see Materials and Methods). Equal current injection at either the dendritic or somatic site gave symmetrical voltage deflections at the reciprocal site (reciprocity), similar to L5 pyramidal neurons, indicating that the apical dendrites of L6 pyramidal neurons behave as linear cables in this voltage range (Fig. 1b3). We also measured the resting membrane potential $\left(R_{\mathrm{m} \_ \text {rest }}\right)$ at both recording sites immediately after breakthrough to whole-cell configuration at the dendrite (Fig. 1c). Surprisingly, dendritic $R_{\mathrm{m} \_ \text {rest }}$ was usually more hyperpolarized than somatic $R_{\mathrm{m} \text { rest }}(-72 \pm 7 \mathrm{mV}$ vs $-68 \pm 8$ $\mathrm{mV}, n=19 ; p=0.001)$. This is in contrast to observations in L5 pyramidal neurons where dendritic $R_{\mathrm{m} \_ \text {rest }}$ is up to $10 \mathrm{mV}$ more depolarized than somatic $R_{\mathrm{m} \_ \text {rest }}$ (Zhu, 2000; Berger et al., 2001; Larkum and Zhu, 2002).

The analysis of the steady-state properties in response to long current injection is summarized in Figure $1 d-g$ and Table 1. Steady-state voltage attenuation was determined by comparing the effective length constant $\left(\lambda_{\text {eff }}\right)$ for the somatopetal direction (dendrite $\rightarrow$ soma) with the somatofugal (soma $\rightarrow$ dendrite) using exponential fits to the data $\left(\lambda_{\text {eff }}=334\right.$ and $501 \mu \mathrm{m}$, respectively) (Fig. 1d). Local membrane time constants were $9.1 \pm 2.1$ $\mathrm{ms}$ for injection at the somatic site $\left(\tau_{\mathrm{m} \_ \text {soma }}\right)$ and $5.7 \pm 1.5 \mathrm{~ms}$ for the dendritic site $\left(\tau_{\mathrm{m} \_ \text {dend }}\right)$ (Fig. $\left.1 c\right)$. Mean input resistance
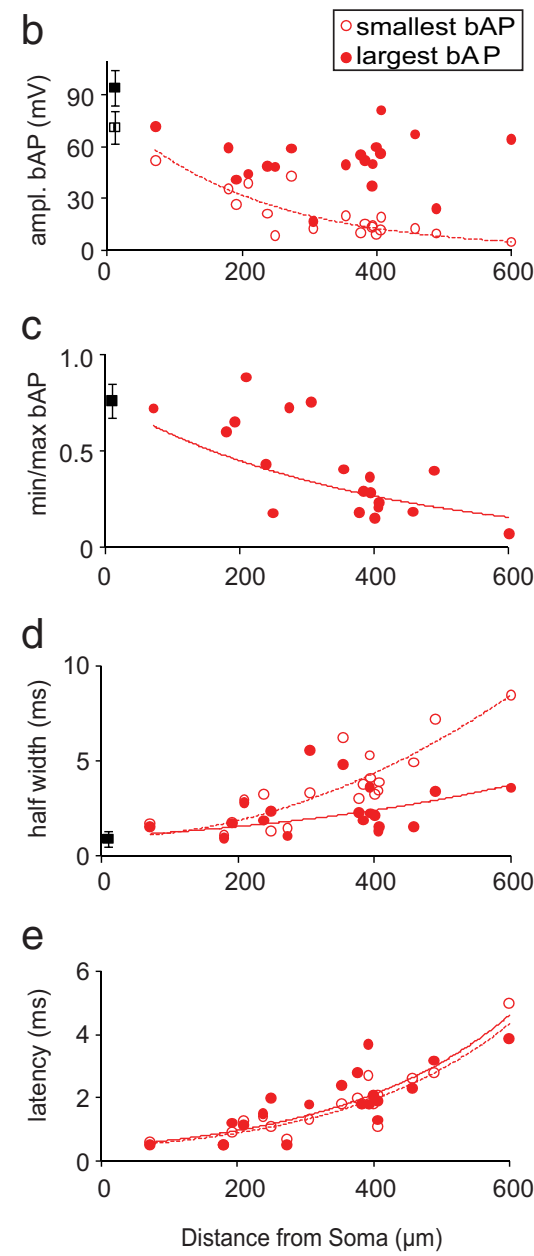

Figure 3. Back propagation of action potentials in a train. $\boldsymbol{a}$, Representative examples from a range of dendritic distances from the soma illustrating dendritic responses to long (1000 ms) somatic current injections at twice rheobase, which evoked a train of train as function of distance from soma. $c$, Ratio of dendritic amplitude of smallest to biggest bAP of the train of somatic APs, $d$, Half-width (d) and latency (e) of smallest (open circles) and largest (filled circles) dendriticbAP amplitudes as a function from soma. Data were fit with a single exponential where possible (dashed line, smallest bAP; solid line, biggest bAP).

$\left(R_{\text {input }}\right)$ at resting membrane potential (see Materials and Methods) in the dendrite was $154 \pm 38 \mathrm{M} \Omega$, which was significantly larger than $R_{\text {input }}$ at the soma $(114 \pm 29 \mathrm{M} \Omega, n=19 ; p=$ $1.8 \cdot 10^{-4}$ ) and did not increase as a function of distance along the dendrite (Fig. 1e). Input resistance is also nearly constant along the apical dendrites of L5 pyramidal neurons where it has been shown to be due to an increasing density of hyperpolarizationactivated cation conductance $\left(I_{\mathrm{h}}\right)$ along the dendrite, which counteracts the decrease in dendritic diameter as a function of distance (Zhu, 2000; Berger et al., 2001). We therefore tested for sag in the dendrites of L6 pyramidal neurons by injecting long hyperpolarizing currents at different locations (Fig. 1b,f). We found a fourfold increase in the sag in the distal regions of the apical dendrite (Fig. $1 g$ ). The increase in $I_{\mathrm{h}}$ could not account for the measured resting membrane potential in the dendrites of L6 neurons as in L5 neurons. This suggests that additional mechanisms determine the final resting membrane potential (see Discussion).

\section{Backpropagation of action potentials}

Injection of short ( $2 \mathrm{~ms}$ ) step pulses to the soma near threshold for AP initiation led to backpropagating APs (bAPs) in the apical 
a
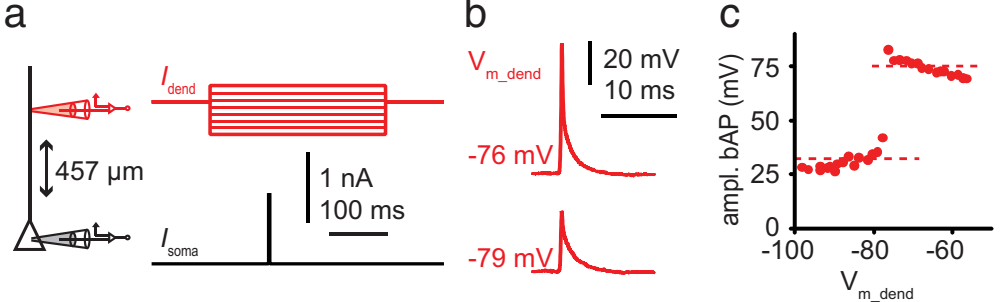

d

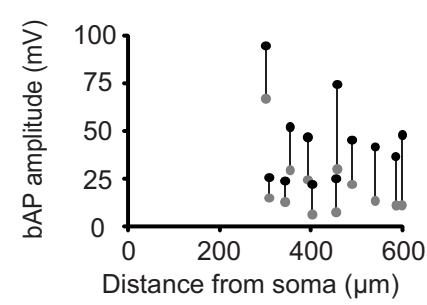

e

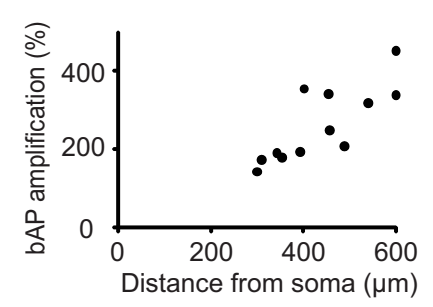

f

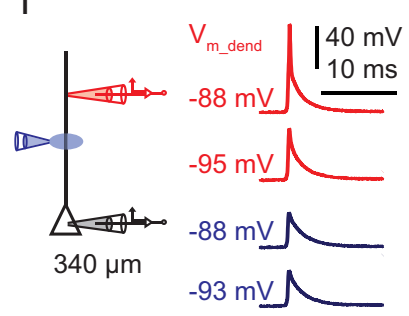

g
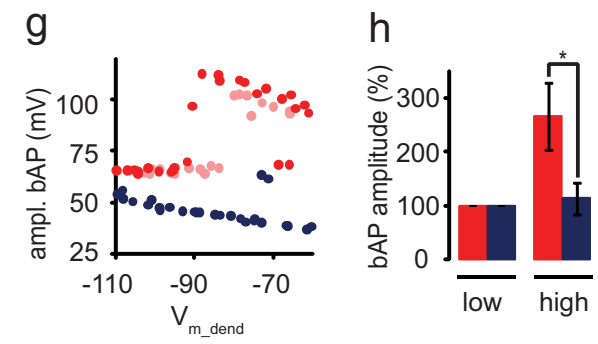

Figure 4. Abrupt increase in bAP amplitude with dendritic current injection dependent on dendritic $\mathrm{Na}^{+}$channels. $\boldsymbol{a}$, Experimental setup with the dendritic electrode in red and the somatic electrode in black. The dendritic membrane potential was controlled by dendritic current injection for $300 \mathrm{~ms}$ with varying amplitude (red traces) starting $100 \mathrm{~ms}$ before a $2 \mathrm{~ms}$ current injection at the soma (black trace) that evoked an AP. $\boldsymbol{b}$, bAPs recorded $457 \mu \mathrm{m}$ from the soma (red traces) at different dendritic membrane potentials $\left(V_{\mathrm{m} \_ \text {dend }}\right)$. $c$, Example of bAP amplitude as a function of $V_{\mathrm{m} \_ \text {dend }}$ in one cell. Dashed lines indicate average values before and after the abrupt increase in amplitude (low and high, respectively). $\boldsymbol{d}$, High (black circles) versus low (gray circles) amplitudes of bAPs in all cells recorded as a function of distance from soma. $\boldsymbol{e}$, Relative amplification of bAP amplitude with respect to the low level as a function of distance from soma. $f$, Left, Experimental setup for local blockade of dendritic $\mathrm{Na}^{+}$channels. Dendritic and somatic recording electrodes are in red and black, respectively, and the TTX puffing pipette is in blue. Right, bAPs recorded $340 \mu \mathrm{m}$ from soma at different $V_{\mathrm{m} \_ \text {dend }}$ in control conditions (red traces) and during the local application of TTX (blue traces). $\boldsymbol{g}$, bAP amplitude as a function of $V_{\mathrm{m}}$ dend of the same cell in control conditions (red circles), after application of TTX (blue circles), and after washout (pink circles). $\boldsymbol{h}$, bAP amplitude in percentage at low and high $V_{\mathrm{m} \_d e n d}$, in control conditions (red bars), and during local application of TTX (blue bars). Asterisk indicates statistical significance using a paired, one-tailed $t$ test $n=3$; $p=0.004)$.

dendrite with decreasing amplitudes as a function of distance (Fig. 2), although variability between cells was high (Fig. $2 b, c$ ). Half-width and latency also increased as a function of distance (Fig. 2d,e). Injection of longer pulses (500-1000 ms) at twice rheobase evoked trains of bAPs that showed AP amplitude adaptation throughout the train (Fig. 3a1-a3). The first 1-5 APs in the train showed variable amplitude adaptation from cell to cell, which then decreased for subsequent APs (Fig. 3a,b). The largest bAP amplitude was always one of the first three APs, with the second or third bAP frequently much larger than the first when the cell emitted an initial high-frequency burst, as in Figure 3a1a3. The following bAP amplitudes were substantially smaller, with the smallest amplitudes at the end of the train. The ratio of minimum to maximum AP amplitude decreased with distance from soma (Fig. 3c). In trains of bAPs, half-width and latency also increased exponentially with distance from the soma, regardless of the variability in amplitude (Fig. $3 d, e$ ). These results suggest that L6 pyramidal neurons can sustain active backpropagation of APs that is strongly influenced by the dendritic membrane potential and the activation state of dendritic sodium channels (Jung et al., 1997).

\section{Mechanisms underlying enhanced backpropagation of APs}

It has been demonstrated in L 5 pyramidal neurons that the amplitude of bAPs is very sensitive to dendritic membrane potential and that AP propagation becomes passive after a certain variable distance (Larkum et al., 2001; Stuart and Häusser, 2001; Vetter et al., 2001). We tested this in L6 neurons by changing the resting membrane potential with steady-state current injection to the dendrite starting $100 \mathrm{~ms}$ before evoking an AP at the soma (Fig. $4 a, b$ ). The amplitude of the bAP measured in the dendrite typically increased in a stepwise manner with long depolarizing current injection into the dendrite (Fig. 4c). This abrupt shift occurred only for recordings $>200 \mu \mathrm{m}$ from the soma in all L6 dendrites tested at these distances $(n=12)$ (Fig. 4d). bAP amplification increased as a function of distance from 141 to $450 \%$ (Fig. 4e). The stepwise increase in bAP amplitude with dendritic depolarization could be blocked by local application of TTX $(1 \mu \mathrm{M})$ to the proximal apical dendrite (200-230 $\mu \mathrm{m}$ from soma) (Fig. $4 f-$ $h$ ), which shows that dendritic voltage gated $\mathrm{Na}^{+}$channels are responsible for the enhancement AP backpropagation.

To understand whether synaptic input can boost backpropagation in a similar way to dendritic depolarization, we also investigated dendritic intracellular $\mathrm{Ca}^{2+}$ $\left(\left[\mathrm{Ca}^{2+}\right]_{\mathrm{i}}\right)$ along the apical dendrite of L6 pyramidal neurons (Fig. 5). Regions of interest (ROI) in $100 \mu \mathrm{m}$ segments along the apical dendrite were compared during a bAP evoked at the soma (Fig. 5a). Under control conditions, bAPs caused increases in dendritic $\left[\mathrm{Ca}^{2+}\right]_{\mathrm{i}}$ at proximal locations $(<\sim 300 \mu \mathrm{m})$ (Fig. 5b,e,f). Synaptic stimulation near $(<10 \mu \mathrm{m})$ the apical dendrite at the border of $\mathrm{L} 5$ and L6 (Fig. 5a) enhanced the influence of bAPs on dendritic $\mathrm{Ca}^{2+}$ influx for most of the length of the dendrite tree (Fig. $5 c, e, f$ ). The synaptic stimulation itself, without the bAP, caused no detectable influx of $\mathrm{Ca}^{2+}$ (Fig. 5d-f). This suggests that dendritic depolarization due to synaptic input also enhances backpropagation in a similar manner to direct dendritic current injection (Häusser et al., 2001).

\section{Dendritic responses to high-frequency trains of bAPs}

Brief trains (or bursts) of bAPs have also been shown to cause abrupt increases in dendritic $\mathrm{Ca}^{2+}$ in L5 and L2/3 pyramidal neurons at a critical frequency (Larkum et al., 1999a, 2007). We tested this phenomenon in L6 pyramidal neurons by somatically generating trains of three APs with $2 \mathrm{~ms}$ current injection at frequencies between 10 and $200 \mathrm{~Hz}$ and recording the resulting bAPs in the dendrite. At low frequencies, bAPs measured in the dendrite showed slight adaptation such that the third bAP in the train was on average $73.1 \pm 23.2 \%$ of the height of the first bAP (Fig. 6a, upper trace). In contrast, at high frequencies, the amplitude of the third bAP increased by $32.7 \pm 15.0 \mathrm{mV}$. This repre- 

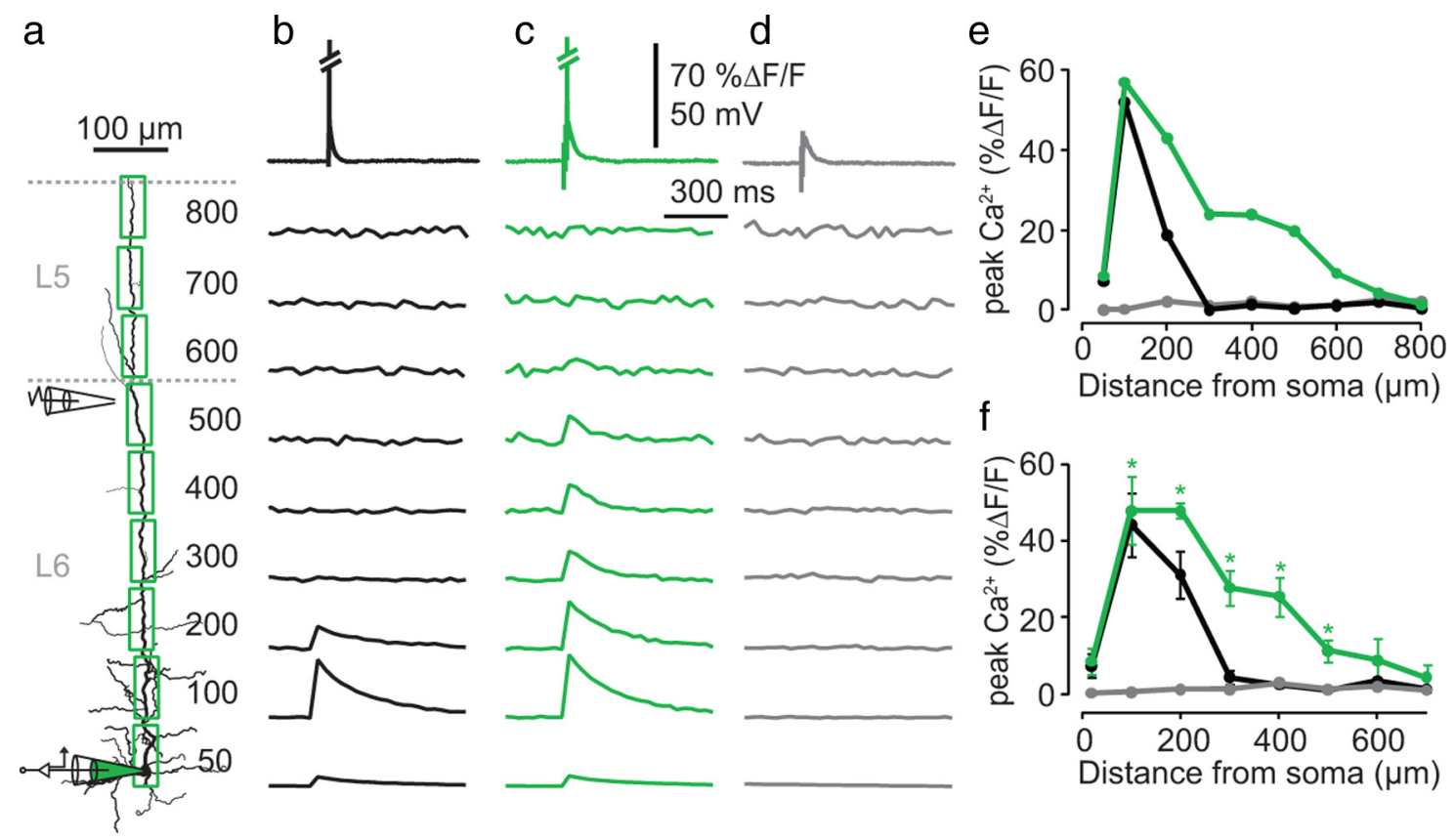

Figure 5. $\mathrm{Ca}^{2+}$ influx along the apical dendrite due to bAPs. $\boldsymbol{a}$, Reconstructed $\mathrm{L} 6$ pyramidal neuron showing the regions of interest used for measuring $\mathrm{Ca}^{2+}$ influx (green squares) along the apical dendrite (numbers to the right indicate the distance from the soma). A somatic recording electrode (green) was used to fill the cell with the calcium indicator $0 \mathrm{~GB}-1$ (100 $\mu \mathrm{m}$ ) and evoke a single bAP. A second extracellular stimulation electrode was placed close to the dendrite ( $<\sim 10 \mu \mathrm{m}$ ) at the border of $\mathrm{L} 5$ and $\mathrm{L} 6 . \boldsymbol{b}$, Example of bAP (top trace) that evoked fluorescence increases (lower traces) for the first $200 \mu \mathrm{m}$ along the apical dendrite under control conditions. Diagonal slashes in top trace indicate truncation of the somatic AP. $c$, bAP-evoked fluorescence measurements along the same dendrite with simultaneous synaptic stimulation. $\boldsymbol{d}$, Synaptic stimulation (top trace) alone showing no detectable $\mathrm{Ca}^{2+}$ influx (bottom traces). $\boldsymbol{e}$, Fluorescence profile for all distances measured in the cell shown in $\boldsymbol{a}-\boldsymbol{d}$. $\boldsymbol{f}$, Average fluorescence profile for five cells. Error bars indicate the SEM. Asterisks indicate statistical significance between the control condition versus synaptic stimulation ( $n=5 ; p=0.007,0.02,0.007,0.006,0.024$, in order from left to right).

sented an increase of $192.2 \pm 64.5 \%$ that occurred at frequencies of $80-200 \mathrm{~Hz}(n=17)$. The critical frequency was defined as the point of inflection of the amplitude increase (see Materials and Methods) (Larkum et al., 1999a). The sharp transition from subcritical to supracritical frequencies suggests a nonlinear recruitment of dendritic current. This current could be detected at the soma in the form of an after-depolarizing potential of $3.1 \pm 1.6$ $\mathrm{mV}$ following the last AP in the train (Fig. $6 b$, lower traces, $d$ ). The after-depolarizing potential recorded at the soma was clearly dependent on the dendritic electrogenesis, since it occurred at the same frequency $(85.9 \pm 24.8 \mathrm{~Hz}$ vs $85.3 \pm 23.6 \mathrm{~Hz}$ for soma and dendrite, respectively; $n=17 ; p=0.79$ ).

Consistent with the observation that dendritic depolarization increased nonlinearly for supracritical frequency trains of APs, we also found large increases in distal dendritic $\left[\mathrm{Ca}^{2+}\right]_{i}$ during high-frequency trains, whereas low-frequency trains caused no change in $\left[\mathrm{Ca}^{2+}\right]_{\mathrm{i}}$ (Fig. $6 \mathrm{c}$ ). The point of inflection for the sigmoidal increase in dendritic $\left[\mathrm{Ca}^{2+}\right]_{\mathrm{i}}$ always occurred near the turning point for the increase in the somatic after-depolarizing potential $(\Delta=2.4 \pm 2.3 \mathrm{~Hz} ; n=5 ; p=0.082)$, reaching a maximum value of $69 \pm 14 \% \Delta \mathrm{F} / \mathrm{F}$ at higher frequencies (Fig. $6 c, e)$. Since there was no significant difference between the critical frequency measured at the dendrite and the soma, we could reliably estimate the average critical frequency in L6 pyramidal neurons by measuring only the after-depolarizing potential change at the soma increasing the sampling size. The average critical frequency for $46 \mathrm{~L} 6$ pyramidal neurons was $96 \pm 24.5 \mathrm{~Hz}$ (Fig. $6 f$ ) and the average additional depolarization at the soma was $2.7 \pm$ $1.6 \mathrm{mV}$ (Fig. $6 \mathrm{~g}$ ). We found no statistically significant difference between the critical frequency measured in CC and CT pyramidal neurons using a two-sample, unequal variance $t$ test $(n=14$ and $n=5$ for CC and CT, respectively; $p=0.477$ ) (supplemental Fig.
$1 k$, available at www.jneurosci.org as supplemental material). The critical frequency of L6 pyramidal neurons was more similar to $\mathrm{L} 5(98 \pm 33 \mathrm{~Hz})$ than to $\mathrm{L} 2 / 3$ neurons $(128 \pm 21 \mathrm{~Hz})$.

\section{Dendritic electrogenesis}

For L2/3 and L5 pyramidal cells, it has been established that the apical dendrite is capable of initiating local dendritic potentials, which may have consequences for the computational properties of the neurons (Amitai et al., 1993; London and Häusser, 2005; Larkum et al., 2007, 2009; Nevian et al., 2007). We therefore investigated whether L6 pyramidal cells also support dendritic spikes and their influence on somatic AP output (Fig. 7). Steadystate current injection (500-1000 ms duration) at different locations along the apical dendrite produced trains of APs at the soma interacting with prolonged depolarizations at the dendrite (Fig. $7 a)$. Similar to both L2/3 and L5 cells, the width of the AP increased as a function of the distance of the dendritic current injection from the soma (Fig. 7b). In L6 cells, this occurred most prominently in a region $\sim 400 \pm 100 \mu \mathrm{m}$ from the soma, where very pronounced dendritic spike durations resembled dendritic plateau potentials (Fig. 7a2,b). For the most distal injection sites (farther than $400 \mu \mathrm{m}$ from the soma), a dendritic spike (an electrogenic potential detected first in the dendrite) led to only one to three somatic APs at the beginning of the current injection (Fig. 7a3).

One defining characteristic of apical dendritic current injection to L5 pyramidal neurons is the transformation of the more regular pattern of spiking elicited by somatic current injection to a more variable mode [sometimes referred to as intrinsically bursting mode (Connors and Gutnick, 1990)]. This transformation was less obvious in L6 pyramidal neurons. However, we could measure a gradual increase in the coefficient of variation of 

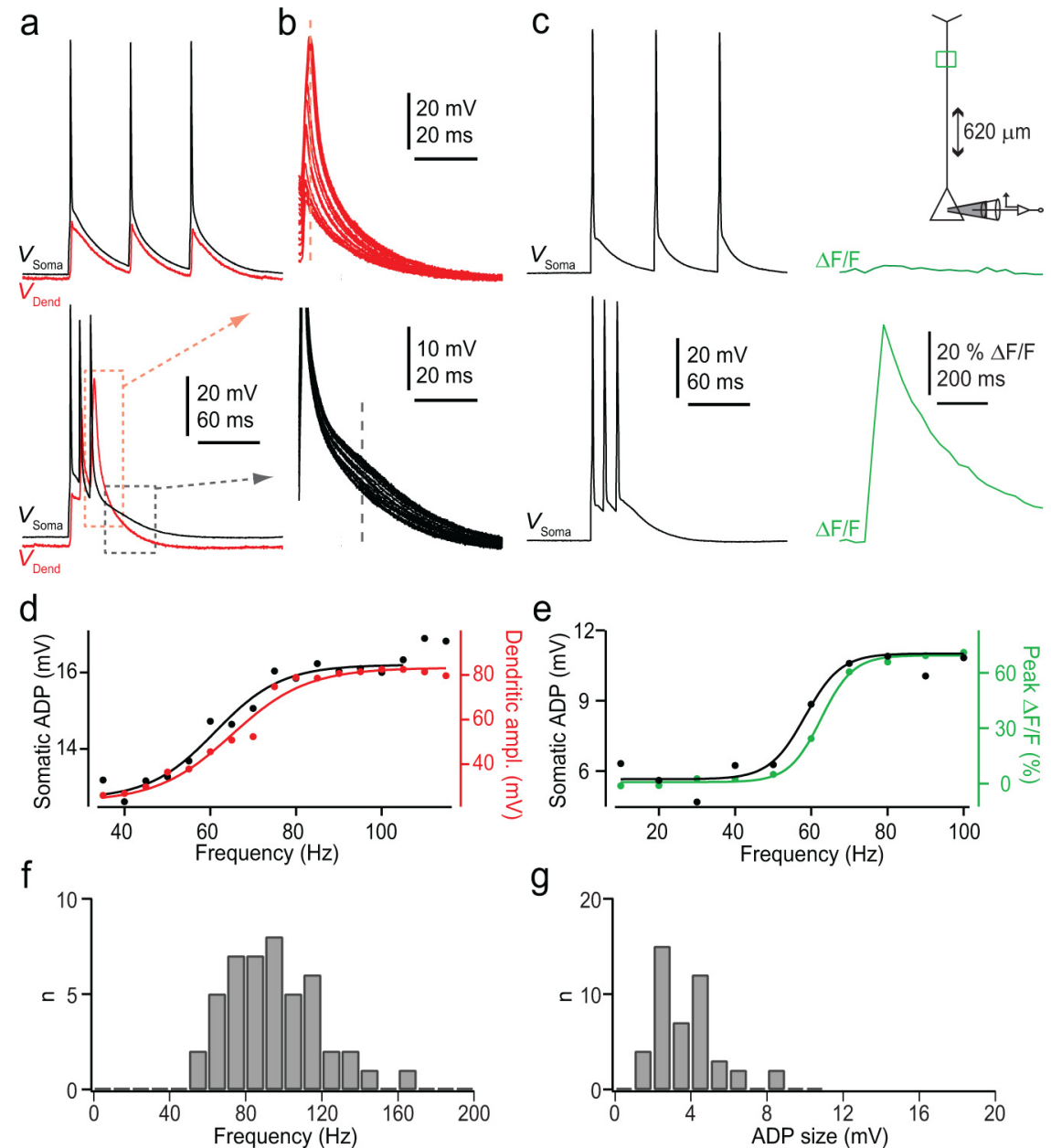

g

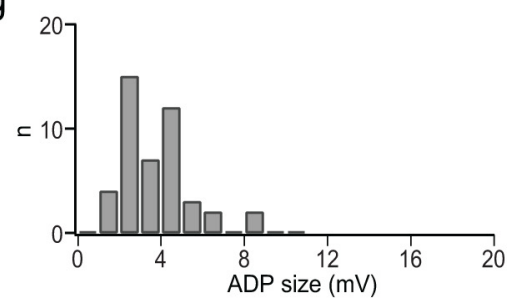

Figure 6. Critical frequency for dendritic electrogenesis. $\boldsymbol{a}$, Dual somatic (black trace) and dendritic (red trace) recordings from a L6 pyramidal neuron. Responses to brief trains of APs at 10 (top) and $140 \mathrm{~Hz}$ (bottom) evoked by three brief somatic current injections ( $2 \mathrm{~ms}$ each). The resting membrane potential at the soma and at the dendrite was -77 and $-82 \mathrm{mV}$, respectively. The soma was $1540 \mu \mathrm{m}$ from pia and the dendritic recording pipette was localized $354 \mu \mathrm{m}$ from soma. $\boldsymbol{b}$, Overlay of the last AP in the train of three APs at different frequencies of 40 to $150 \mathrm{~Hz}$ for dendritic (top) and somatic (bottom) recording. The peak amplitude (and width) of the last AP recorded at the dendrite increased in a nonlinear manner. This was also reflected in an increase in depolarization after the last AP (ADP) at the soma (time point indicated by the dashed line). $c$, Measurements of $\left[\mathrm{Ca}^{2+}\right]_{\mathrm{i}}$ in a region of interest (green box) in the apical dendrite following low (top) and high (bottom) frequency trains of APs as in $\boldsymbol{a}$ and $\boldsymbol{b}$. $\boldsymbol{d}$, Dendritic and somatic potentials measured at the time point indicated with dashed lines in $\boldsymbol{a}$ and $\boldsymbol{b}$ shown as a function of AP frequency. $\boldsymbol{e}$, Somatic after-depolarizing potential and fluorescence measurements from c shown as a function of AP frequency. $\boldsymbol{f}$, Histogram of critical frequency measured from 46 neurons. $\boldsymbol{g}$, Histogram of somatic after-depolarizing potential values from the same neurons as in $\boldsymbol{f}$.

the interspike interval as a function of distance (Fig. $7 c$ ). The increase in variability occurred in approximately the same region as the longest dendritic plateau potentials. Interestingly, the threshold current needed to bring the cell to fire with long current injection increased linearly but only slightly as a function of distance (Fig. $7 d$ ) and showed no prominent decrease in the apical trunk (Fig. 7e) as seen in L5 pyramidal neurons (Larkum and Zhu, 2002).

Local dendritic spikes can be more robustly elicited in some pyramidal cell types with shorter current injection resembling large, local, and synchronous synaptic inputs (Gasparini et al., 2004; Larkum et al., 2007). We therefore also tested dendritic spike initiation using waveforms resembling compound EPSCs at the dendritic electrode with a double-exponential current waveform $\left(\tau_{1}=2\right.$ and $\tau_{2}=8 \mathrm{~ms}$; see Materials and Methods) resulting in a time to peak of $\sim 3.5 \mathrm{~ms}$. Injection of progressively increasing current amplitudes led to local dendritic spikes that could have

multiple components at higher current injections (Fig. 8a-c). In 17 of 17 cells, threshold current injection $(767 \pm 356$ pA) evoked a single component dendritic spike (Fig. 8b, upper red trace) that occurred first at the dendritic electrode. In 12 of 17 cells, we observed a second component of the dendritic spike at a threshold of $817 \pm 175$ pA (Fig. $8 c$, upper red trace). Further current injection frequently led to initiation of a somatic AP, which propagated back into the dendrite (average threshold, $1121 \pm 535 \mathrm{pA}$ ) (Fig. $8 d$ ). At locations along the apical dendrite close to the cell body (corresponding to regions within L6), it was only possible to evoke single component spikes, whereas both one- and two-component spikes could be evoked at more distal locations ( $>300 \mu \mathrm{m}$ from the soma corresponding approximately to L5 and L4) (Fig. 8e,f). The amplitude of the EPSC necessary to evoke a single component spike decreased linearly with distance from soma (Fig. $8 f$ ). The current threshold to evoke a dendritic spike relative to the threshold for the dendritic current to evoke a somatic AP can be used as an indication of the somatodendritic coupling. For distances greater than $\sim 200 \mu \mathrm{m}$, this ratio fell below 1 , indicating that input beyond these distances is more likely to generate local dendritic spikes (Fig. 8g). The shape of the single component spikes resembled voltagegated sodium channel-dependent potentials seen in L5 and CA1 pyramidal neurons (Golding and Spruston, 1998; Larkum et al., 2001; Gasparini et al., 2004), whereas the second component was broader. We investigated the underlying currents for both components by applying the voltage-gated $\mathrm{Na}^{+}$channel blocker, TTX, and voltage-gated $\mathrm{Ca}^{2+}$ channel blockers, $\mathrm{Cd}^{2+}$ and $\mathrm{Ni}^{2+}$ (Fig. $8 h-j) \cdot \mathrm{Cd}^{2+}(50 \mu \mathrm{M})$ and $\mathrm{Ni}^{2+}(100 \mu \mathrm{M})$ blocked the second component $(n=3$; $p=0.02)$ but spared the first component, which was then blocked by additional application of TTX $(1 \mu \mathrm{M} ; n=3$; $p=$ 0.001 ), indicating that the first component is mediated predominantly by voltage-gated $\mathrm{Na}^{+}$channels, whereas the second component depends on voltage-gated $\mathrm{Ca}^{2+}$ channels in the dendritic membrane.

The location of the basal and apical dendritic arbors of L6 pyramidal neurons places them in a unique position with respect to thalamocortical and corticocortical projections. It is therefore interesting to examine whether L6 pyramidal neurons share the associative properties of other pyramidal neurons in terms of the signaling between the distal and proximal compartments (Larkum et al., 1999a,b). We tested this by combining an EPSC waveform injection at the dendrite (Fig. 9a1) with a bAP generated at the soma (Fig. 9a2). A single bAP reduced the threshold for the dendritic spike to $77 \pm 16 \%(n=5 ; p=0.017)$ of the control value (Fig. 9) when the EPSC followed the bAP by $5 \mathrm{~ms}$. 
Synaptically evoked electrogenesis

Extracellular stimulation of L5 pyramidal cell dendrites can evoke local NMDA spikes in trains of two or more stimuli at $50 \mathrm{~Hz}$ (Schiller et al., 2000), which can be most readily evoked in thin basal or tuft dendrites $<1.5 \mu \mathrm{m}$ in diameter (Larkum et al., 2009). Since we found that the average diameter of the L6 apical dendrite is $1.33 \pm 0.22 \mu \mathrm{m}$ (see Fig. 12), we tested whether similar synaptically evoked electrogenesis occurs in these dendrites by stimulating with two extracellular pulses at $50 \mathrm{~Hz}, 404-600 \mu \mathrm{m}$ from the soma (Fig. 10a). Stimulation above a threshold level (High) (Fig. 10c) led to plateau-like potentials recorded at the soma that were blocked by the addition of $50 \mu \mathrm{M}$ AP- 5 to the bath (Fig. 10b-d). The integral of the subthreshold (Low) EPSPs remained the same after AP-5 $(n=5 ; p=0.38)$. The maximum duration of the plateau-like potential evoked by synaptic stimulation at the soma was 36-55 ms (average $43.9 \pm$ $7.4 \mathrm{~ms} ; n=5$ ) and did not resemble the second component of the electrogenic response to direct dendritic current injection (Fig. 8). Further stimulation under AP-5 at levels approximately twice the control threshold did not evoke any apparent broadening of the second EPSP. This suggests that synaptic stimulation evokes an additional NMDA-dependent regenerative component as in the distal tufts of L5 pyramidal neurons. We also observed similar potentials when stimulating the basal dendrites in exactly the same manner ( $n=3$, data not shown).

\section{Inhibitory control of calcium electrogenesis}

Dendritic inhibition has been shown to powerfully block dendritic $\mathrm{Ca}^{2+}$ electrogenesis in neocortical and hippocampal pyramidal neurons (Buzsáki et al., 1996; Miles et al., 1996; Pérez-Garci et al., 2006; Larkum et al., 2007; Murayama et al., 2009). To investigate the effect of inhibition on dendritic regenerative events in L6 pyramidal neurons, we evoked dendritic $\mathrm{Ca}^{2+}$ influx using a supracritical frequency burst of three bAPs (Fig. 6). A compound IPSP was generated in the presence of blockers for excitatory synaptic transmission ( $50 \mu \mathrm{M} \mathrm{AP}-5$ and 10 $\mu \mathrm{M}$ CNQX) with an extracellular electrode placed in upper L5 or L4, $\sim 200 \mu \mathrm{m}$ lateral to the distal L6 pyramidal dendrites (Fig. 11a). Five pulses at $200 \mathrm{~Hz}$ were delivered to the extracellular stimulating electrode at $\Delta t=-500$ to $50 \mathrm{~ms}$ relative to the burst of APs at the soma (Fig. 11b). Dendritic $\left[\mathrm{Ca}^{2+}\right]_{\mathrm{i}}$ was measured as described above in a region of interest (Fig. 11a, green ROI) $\sim 400 \mu \mathrm{m}$ from the soma (Fig. 11c). The peak change in fluorescence $(\Delta \mathrm{F} / \mathrm{F})$ decreased to nearly zero as $\Delta t$ approached zero (i.e., simultaneous extracellular stimulation and AP burst) (Fig. $11 c-e$; red trace) $(n=5)$. Addition of the $\mathrm{GABA}_{\mathrm{B}}$ receptor blocker CGP $52432(1 \mu \mathrm{M})$ reduced the effective time window for dendritic inhibition from $\sim 400$ to $100 \mathrm{~ms}$ b
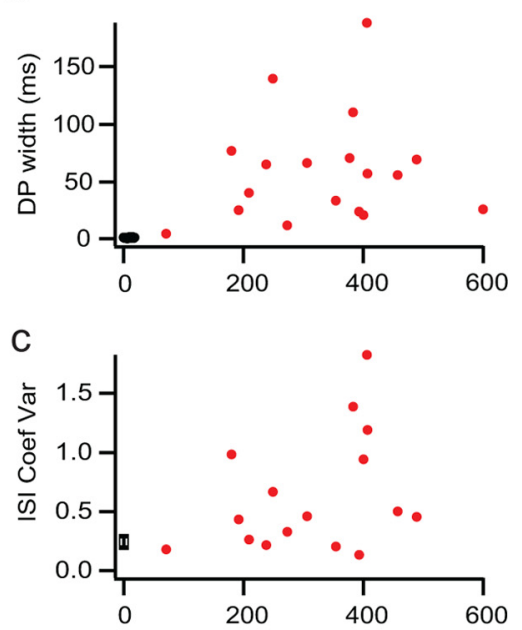

d
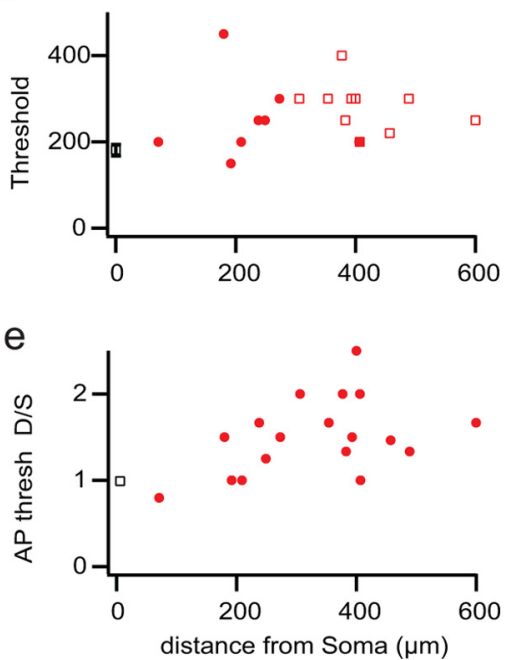

Figure 7. Dendritic electrogenesis evoked by long current injection to the distal dendrite and its interaction with somatic action potentials. $\boldsymbol{a}$, Long (1 s) dendritic current injections near threshold evoking different somatic AP response patterns depending on the distance of dendritic injection site from the soma (electrode placement shown schematically on the left). $\boldsymbol{b}$, Width of dendritic potentials (DP), including bAPs with dendritic current injection (see Materials and Methods). $\boldsymbol{b}-\boldsymbol{e}$, Black squares represent the (coefficient of variation of interspike interval over the entire duration of current injection) due to steady-state current injection as a function of the distance of injection site from the soma. $\boldsymbol{d}$, Threshold current injection to evoke one or more APs. In some cases, the first AP was initiated at the soma (filled circles) and in other cases at the dendrite (open squares). $e$, Threshold current required for generating somatic APs with long current injection at the dendrite (D) in proportion to threshold for APs with long current injection at soma (S).

(Fig. 11d,e, blue trace). Further addition of the $\mathrm{GABA}_{\mathrm{A}}$ receptor blocker gabazine $(3 \mu \mathrm{M})$ completely abolished the remaining inhibition of $\left[\mathrm{Ca}^{2+}\right]_{\mathrm{i}}$ for the subsequent times (Fig. 11d,e, black trace). The strength of the extracellular stimulus was adjusted for each experiment so that, at the most effective time $(\Delta t=0)$, the dendritic $\left[\mathrm{Ca}^{2+}\right]_{\mathrm{i}}$ response to the high-frequency burst of APs was reduced to $33 \%$ or lower of the control value. At this strength, the resulting IPSP measured at the soma was very small $(-0.8$ to $-2.8 \mathrm{mV})$ and, for most cells (4 of 5), the inhibition of dendritic $\left[\mathrm{Ca}^{2+}\right]_{\mathrm{i}}$ outlasted the duration of the IPSP $(249.6 \pm 115 \mathrm{~ms} ; n=5)$, suggesting that the inhibitory mechanisms include block via $\mathrm{GABA}_{\mathrm{B}}$-mediated $\mathrm{Ca}^{2+}$ channel inactivation as has been shown in L5 neurons (Pérez-Garci, 2006). The results show that, similar to other pyramidal neurons, dendritic inhibition can also powerfully suppress dendritic $\mathrm{Ca}^{2+}$ electrogenesis in L6 pyramidal neurons via both $\mathrm{GABA}_{\mathrm{A}}$ and $\mathrm{GABA}_{\mathrm{B}}$ receptor activation. 

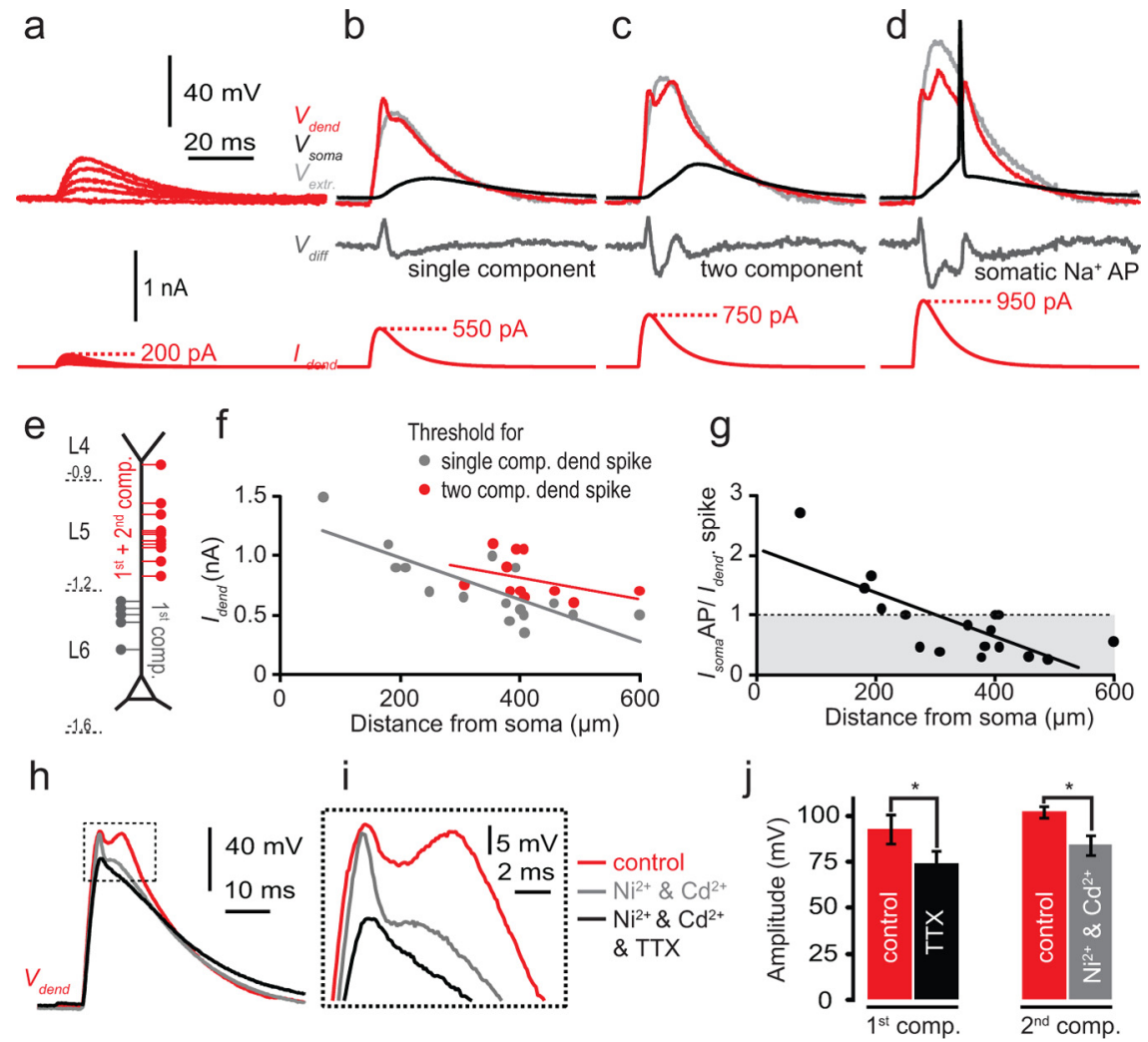

Figure 8. Dendritic spikes generated by EPSC-like current injection to the dendrite. $\boldsymbol{a}-\boldsymbol{d}$, Dual recording from the soma and dendrite (at a dendritic distance of $383 \mu \mathrm{m}$ ). Dendritic EPSC waveform current injections (bottom red traces) evoked voltage deflections in the dendrite (top red traces, $V_{\text {dend }}$ ) and soma (top black traces, $V_{\text {soma }}$ ). $\boldsymbol{a}$, Subthreshold EPSC waveform current injection (bottom) evoked similarly shaped voltage deflections in the dendrite (top, red trace). $\boldsymbol{b}$, Dendritic spike with a fast initial component generated with a peak EPSC amplitude of $550 \mathrm{pA}$. The extrapolated passive response at suprathreshold EPSC amplitudes is shown in gray in $\boldsymbol{b}$ to $\boldsymbol{d}\left(V_{\text {extr }}\right)$. This was used to calculate the active component of the response $\left(V_{\text {diff }}\right)$ by subtracting $V_{\text {extr }}$ from $V_{\text {dend }}$ (middle, dark gray line) $c$, Dendritic spike with two components generated with increased current injection $(750 \mathrm{pA})$ in the same cell as $\boldsymbol{b}$. $\boldsymbol{d}$, Threshold for a somatic AP in the same cell reached with a $950 \mathrm{pA}$ dendritic current injection. $\boldsymbol{e}$, Diagrammatic representation of the locations of the dendritic current injection that evoked single- and two-component dendritic spikes. The second component could only be generated with current injection more distal than $250 \mu \mathrm{m}$ from soma, which typically corresponds to the region of the dendrite reaching into $\mathrm{L} 5$ and $\mathrm{L} 4$. $f$, Threshold in $\mathrm{nA}$ for the single-component (gray circles) and the two-component (red circles) dendritic spike as a function of distance from soma. Linear fits to the data show the progressive decrease in threshold for initiation of single- and two-component dendritic spikes. $\boldsymbol{g}$, Ratio of the thresholds for the generation of dendritic spikes $\left(I_{\text {dend }}\right)$ versus somatic APs $\left(I_{\text {somaAP }}\right)$ via dendritic current injection. The intersection of the linear fit to the data and the dotted line $\left(I_{\text {somaAP }} / I_{\text {dend }}=1\right)$ indicates the approximate position along the apical dendrite where dendritic spikes tend to precede somatic APs or occur in isolation. $\boldsymbol{h}$, An example of a two-component dendritic spike (red) evoked by EPCS waveform current injection to the dendrite that was reduced to a one-component dendritic spike (gray) by the bath application of $\mathrm{Ni}^{2+}(100$ $\mu \mathrm{m})$ and $\mathrm{Cd}^{2+}(50 \mu \mathrm{m})$. Application of TTX (1 $\mu \mathrm{m}$; black) blocked the remaining component. $i$, Enlarged view of the region inside the dashed box in $\boldsymbol{h}$. $\boldsymbol{j}$. Average amplitudes of the first and second components before and after application of drugs $(n=3)$.

\section{Discussion}

The properties of L6 pyramidal neuron dendrites are of particular interest because of their unique position in the architecture of the neocortex. The dendrites of pyramidal neurons from L 5 and L2/3 have been the subject of investigation for over a decade (Amitai et al., 1993; Kim and Connors, 1993; Stuart and Sakmann, 1994; Svoboda et al., 1997, 1999; Waters et al., 2003) and their diverse properties have been the source of many theories and speculation about cortical function (Eccles, 1992; Mel, 1993; Archie and Mel, 2000; Häusser et al., 2000; Siegel et al., 2000; London and Häusser, 2005; Shlosberg et al., 2006; Spruston, 2008). These include properties such as the nature of backpropagation of APs, concomitant influx of $\mathrm{Ca}^{2+}$ ions, local spike electrogenesis and dendritic inhibition. L6 is the only other layer of the cortex containing predominantly pyramidal neurons. There were therefore prior questions and expectations about L6 versus L2/3 and L5 pyramidal neurons.

Our general finding is that the properties of the apical dendrite of L6 pyramidal neurons in somatosensory cortex bear many similarities to L5 and L2/3 apical dendrites, including active sodium-channeldependent backpropagation with concomitant calcium influx, local calcium and sodium spike initiation, a critical frequency of bAPs for calcium electrogenesis, NMDA-dependent electrogenesis, longacting $\mathrm{GABA}_{\mathrm{A}}$, and $\mathrm{GABA}_{\mathrm{B}}$ inhibition of dendritic calcium electrogenesis (Table $2)$. Despite the similarities in dendritic properties, the function of L6 pyramidal neurons in the cortical circuitry is likely to diverge considerably from other pyramidal neurons because their distal apical and basal dendrites receive synaptic input in other layers (L4 and L6), which in turn receive specific inputs that differ from, for example, L1 (Felleman and Van Essen, 1991).

L6 pyramidal neurons also participate in a dialogue with thalamic and reticular nuclei (Chmielowska et al., 1989; Deschênes et al., 1998; Llinás and Ribary, 2001; Sherman and Guillery, 2002; Alitto and Usrey, 2003; Reichova and Sherman, 2004), which might dictate the spatiotemporal dynamics of input to their dendrites, because the output of the L6 neurons will alter the firing of thalamic neurons influencing, in turn, reentry input to the L6 dendrites. Moreover, other studies have found differences in thalamic-projecting L6 neurons (CT) and cortical-projecting L6 neurons (CC) in their firing output patterns (Mercer et al., 2005; Kumar and Ohana, 2008). We were therefore interested to see whether the dendritic properties of CT and CC neurons also differ. Most of the dendritic properties we observed were relatively homogenously distributed and we saw no evidence for a dichotomy between the classes of L6 neurons (supplemental Fig. 1, available at www.jneurosci.org as supplemental material). This apparent similarity implies that dendritic computation in L6 pyramidal neurons is largely independent of their projection targets.

\section{Passive properties}

We found that L6 pyramidal neurons have a higher input resistance $(114 \mathrm{M} \Omega$ ) at the cell body than L2/3 (47 M $\Omega$ ) (Waters et al., 2003) or L5 (41 M $\Omega$ ) (Zhu, 2000) pyramidal neurons, which is consistent with other studies (Mason and Larkman, 1990; Stuart and Spruston, 1998; Larkum et al., 2007; Kumar and Ohana, 2008). Although the larger input resistance of L6 neurons would tend to make them electrically more compact, this is counterbalanced by the fact that the apical shaft of L6 neurons is proportionally thinner (i.e., the ratio of diameter to length) than in L2/3 

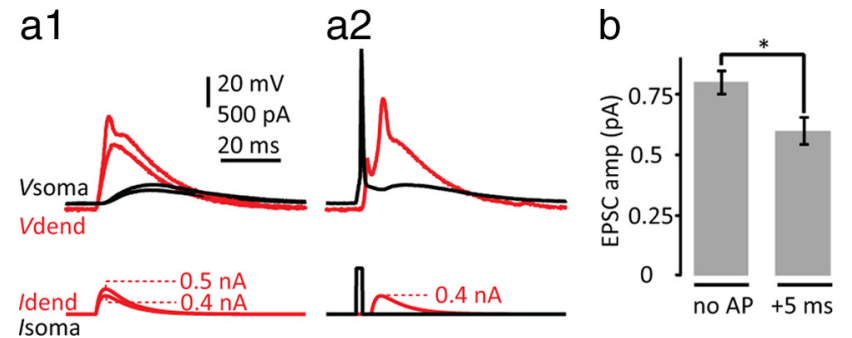

Figure 9. Facilitation of dendritic spikes in L6 neurons with backpropagating APs. a1, EPSC current injection just below and at threshold to the dendrite ( $383 \mu \mathrm{m}$ from the soma) recorded at the dendrite (red trace, $V_{\text {dend }}$ ) and soma (black trace, $V_{\text {soma }}$ ). $\boldsymbol{a 2}$, The subthreshold dendritic EPSP current injection $5 \mathrm{~ms}$ following a somatically evoked backpropagating AP produced a local dendritic spike. $\boldsymbol{b}$, Average dendritic current threshold for a dendritic spike with the injection of dendritic current alone (left, no AP) and following a backpropagating AP (right, $5 \mathrm{~ms}$ ). Asterisk indicates statistical significance $(p=0.017 ; n=6)$.

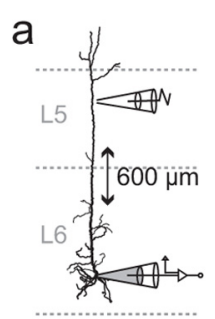

C

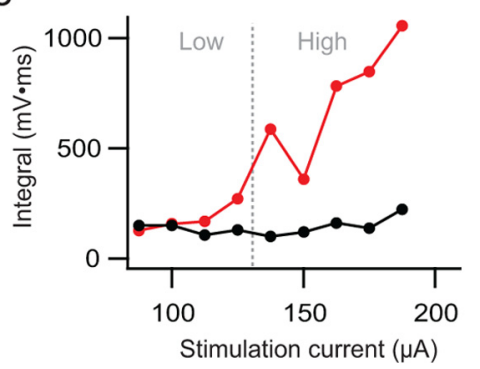

b

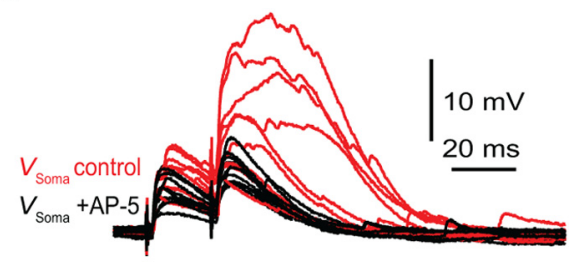

d

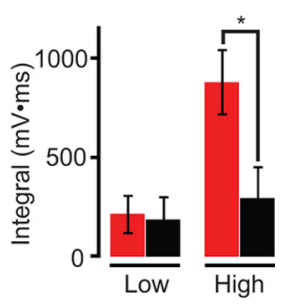

Figure 10. AP-5-sensitive spikes evoked in the distal apical dendrites of $L 6$ pyramidal neurons. $\boldsymbol{a}$, Experiment setup with a somatic recording electrode (gray) and a distally located extracellular stimulating electrode close $(<\sim 5 \mu \mathrm{m})$ to the apical dendrite. Gabazine $(0.1 \mu \mathrm{m})$ was added to reduce the inhibitory transmission. $\boldsymbol{b}$, Two extracellularly evoked EPSPs at $50 \mathrm{~Hz}$ with progressively increasing stimulus strength up to $200 \mu \mathrm{A}$ (red traces). AP-5 (50 $\mu \mathrm{m}$; black traces) blocked the large increase in amplitude and duration of the second EPSP but had only a small effect on the first EPSP. $\boldsymbol{c}$, Integral of the second EPSP shown in $\boldsymbol{b}$ as a function of stimulus strength. $\boldsymbol{d}$, Average integral of the second EPSP for five cells. "Low" and "High" refer to response below and above threshold (dashed gray line in c), respectively, for plateau-like responses. Asterisk indicates statistical significance $(n=5 ; p=0.013)$.

and L5 neurons (Fig. 12). In fact, steady-state signals propagating from the distal apical dendrite to the soma of L6 pyramidal neurons were more greatly attenuated than in L2/3 and L5 neurons (Fig. 12b) (Williams, 2004; Larkum et al., 2007). The electrical isolation of the distal apical dendrite emphasizes the importance of active propagation of signals in L6 pyramidal dendrites (see below).

Another interesting aspect of the passive properties of L6 pyramidal neurons was the relative resting $V_{\mathrm{m}}$ in the dendrite versus the soma. In L5 pyramidal neurons, the substantial increase in $I_{\mathrm{h}}$ channel density in the tuft dendrite has been shown to be responsible for the tonic $6 \mathrm{mV}$ depolarization in the tuft relative to the soma (Berger et al., 2001). L2/3 pyramidal neurons, which do not have this large gradient in $I_{\mathrm{h}}$, also do not have the corresponding gradient in resting $V_{\mathrm{m}}$ (Larkum et al., 2007). We found evidence for $I_{\mathrm{h}}$ in the apical dendrites of L6 pyramidal neurons in the form of a more pronounced sag in response to hyperpolarizing current injection at the dendrite than at the soma. In this respect, it is surprising that the resting $V_{\mathrm{m}}$ in the dendrite is slightly hyperpolarized relative to the soma. This implies that additional mechanisms counteract the effect of $I_{\mathrm{h}}$ on dendritic $V_{\mathrm{m}}$ in L6 pyramidal neurons, e.g., gradients in voltage-sensitive potassium channels along the dendrite and/or different activation states for dendritic channels (Hoffman et al., 1997).

\section{Active properties}

We show evidence for active support of backpropagating APs along the L6 pyramidal neuron apical dendrite by dendritic $\mathrm{Na}^{+}$ channels. The observed strong AP amplitude adaptation in trains of APs is also seen in L5 pyramidal neurons (Larkum et al., 2001) but not in L2/3 pyramidal neurons (Larkum et al., 2007). The AP amplitude was strongly sensitive to resting $V_{\mathrm{m}}$ in the apical dendrite, similar to L5 pyramidal neurons. However, in L6 neurons the boosting occurred more nonlinearly and abruptly at a given dendritic $V_{\mathrm{m}}$ (Larkum et al., 2001; Stuart and Häusser, 2001). This may indicate that the AP fails completely at a sharply defined location along the apical dendrite, which can be overcome or shifted to more distal locations by depolarizing the dendrite (Vetter et al., 2001). We also found an anomalous increase in AP amplitude in the first few APs in the train in some L6 neurons, which has never been seen in other neocortical pyramidal neurons. This might indicate that the point of failure for effective backpropagation in L6 pyramidal neuron is close enough to the soma that somatic depolarization can influence it. A similar anomalous increase was observed in rat olfactory cortical and turtle cortex pyramidal neurons (Larkum et al., 2008; Bathellier et al., 2009).

Even with enhanced backpropagation, single bAPs caused little $\mathrm{Ca}^{2+}$ influx into the distal apical dendrites compared with trains of three to four APs at supracritical frequencies (Figs. $5 c$, $6 c$ ). This is similar to all pyramidal neurons so far tested in $\mathrm{L} 2 / 3$ and L5 of the somatosensory cortex and L5 of the prefrontal cortex (Larkum et al., 1999a, 2007; Gulledge and Stuart, 2003; Waters et al., 2003; Pérez-Garci et al., 2006; Barth et al., 2008). The frequency of APs at which this occurred in L6 pyramidal neurons was most similar to L5 of the somatosensory cortex (Larkum et al., 1999a, 2007; Gulledge and Stuart, 2003; Waters et al., 2003; Pérez-Garci et al., 2006; Barth et al., 2008). The mechanism underlying the critical frequency is most likely related to the accumulated dendritic depolarization that occurs progressively at higher frequencies. In both L5 and L6 pyramidal neurons, the effectiveness of backpropagation is dependent on dendritic resting membrane potential, which may influence the critical frequency. However, since single bAPs caused less increase in distal $\left[\mathrm{Ca}^{2+}\right]_{\mathrm{i}}$ than bursts of bAPs, it is likely that additional mechanisms, such as the activation of high-threshold $\mathrm{Ca}^{2+}$ channels due to prolonged depolarization, are also recruited for this phenomenon. It remains to be tested whether the enhancement of dendritic $\left[\mathrm{Ca}^{2+}\right]_{\mathrm{i}}$ during high-frequency trains of APs leads to the potentiation of synapses on to the distal apical dendrite in L6 pyramidal neurons similar to L5, L2/3, and CA1 pyramidal neurons (Pike et al., 1999; Froemke and Dan, 2002; Letzkus et al., 2005; Sjöström and Häusser, 2006).

We showed that synaptically evoked spikes in the apical dendrite have a strong NMDA regenerative component that closely resembles NMDA spikes in L5 neurons (Schiller et al., 2000; Larkum et al., 2009). In L5 neurons, NMDA spikes can also be evoked by uncaging glutamate locally on tuft branches in the presence of $\mathrm{Ca}^{2+}$ channel blockers, which isolates the responsible 
a

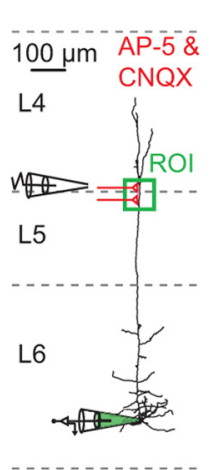

b

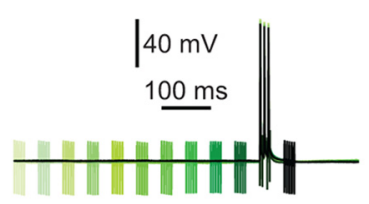

C

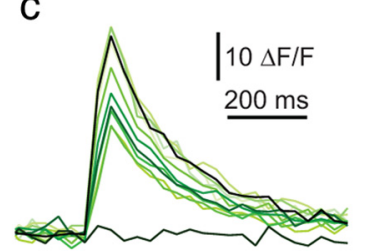

d

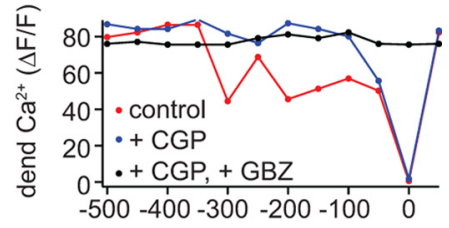

e

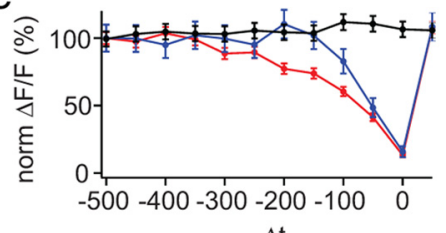

$\Delta t$

Figure 11. Activation of distal inhibitory inputs induces a long-lasting blockade of dendritic $\mathrm{Ca}^{2+}$ electrogenesis. $\boldsymbol{a}$, Experimental arrangement: somatic whole-cell recordings were made with a pipette containing 0GB-1 (100 $\mu$ m; bottom, green) while monitoring $\Delta \mathrm{F} / \mathrm{F}$ at an $\mathrm{ROI}$ on the apical dendrite $\sim 400 \mu \mathrm{m}$ from soma (green box). An extracellular bipolar electrode was placed in L4 $150 \mu \mathrm{m}$ lateral to the apical dendrite to evoke inhibitory input (represented schematically in red). CNQX (10 $\mu \mathrm{M})$ and AP-5 $(50 \mu \mathrm{m})$ were included in the extracellular bathing solution to prevent excitatory synaptic transmission. $\boldsymbol{b}$, Electrical recordings from the soma (black trace) while evoking a train of three APs at $120 \mathrm{~Hz}$ with somatic current injection ( 2 ms pulses of $1 \mathrm{nA}$; critical frequency of the cell shown in this example was $84 \mathrm{~Hz}$ ). The compound IPSP was concurrently evoked by five pulses at $200 \mathrm{~Hz}$. The time of the extracellular stimulation was altered in steps of $50 \mathrm{~ms}$ from 500 before to $50 \mathrm{~ms}$ after the train of action potentials (green to black traces). $\boldsymbol{c}$, Gradual blockade of distal $\mathrm{Ca}^{2+}$ transients recorded in the distal ROI. $\boldsymbol{d}$, Peak amplitudes of $\Delta \mathrm{F} / \mathrm{F}$ as a function of the time interval between the extracellular stimulation and the train of somatic $\operatorname{APs}(\Delta t)$ for the example shown in $\boldsymbol{a}-\boldsymbol{c}$. Measurements were obtained in control conditions (red) and in the presence of the GABA antagonist CGP 52432 ( $1 \mu \mathrm{m}$; blue) and after further addition of the $\mathrm{GABA}_{\mathrm{A}}$ antagonist gabazine (GBZ; $3 \mu \mathrm{m}$; black). $\boldsymbol{e}$, Average inhibition curve for five cells as in $\boldsymbol{d}$.

Table 2. Comparison of the dendritic properties of neocortical pyramidal neurons in different lamina

\begin{tabular}{|c|c|c|c|}
\hline & Layer 2/3 & Layer 5 & Layer 6 \\
\hline $\mathrm{Na}^{+}$channels & $\sqrt{1}$ & $\sqrt{2,3}$ & $\sqrt{ }$ \\
\hline $\mathrm{Ca}^{2+}$ channels & $\sqrt{1}$ & $\sqrt{2,3,4,5,6}$ & $\sqrt{ }$ \\
\hline $\mathrm{K}^{+}$channels & $(\sqrt{ })^{1}$ & $\sqrt{7,8}$ & $(\sqrt{ })$ \\
\hline Active bAPs & $\sqrt{1}$ & $\sqrt{2}$ & $\sqrt{ }$ \\
\hline Critical frequency & $120^{9}$ & $98^{10}$ & 96 \\
\hline Local $^{+}{ }^{+}$spike & $\sqrt{ }{ }^{9}$ & $\sqrt{3,11}$ & $\sqrt{ }$ \\
\hline Local $\mathrm{Ca}^{2+}$ spike & $(\sqrt{ })$ short $^{9}$ & $\sqrt{ } 2,3,4$ & $\sqrt{\text { short }}$ \\
\hline Local NMDA spike & $\sqrt{ }$ (basal) $^{12}$ & $\sqrt{11,13}$ & $\sqrt{ }$ \\
\hline BAC firing & $\sqrt{9}$ & $\sqrt{14}$ & $\sqrt{ }$ \\
\hline
\end{tabular}

Parentheses indicate that only indirect evidence is available. ${ }^{1}$ Waters et al. (2003); ${ }^{2}$ Stuart and Sakmann (1994); ${ }^{3}$ Larkum et al. (2001); ${ }^{4}$ Schiller et al. (1997); ${ }^{5}$ Markram et al. (1995); ${ }^{7}$ Korngreen and Sakmann (2000); ${ }^{8}$ Bekkers (2000); ${ }^{9}$ Larkum et al. (2007); ${ }^{10}$ Larkum et al. (1999a); ${ }^{11}$ Nevian et al. (2007); ${ }^{12}$ Gordon et al. (2006); ${ }^{13}$ Larkum et al. (2009); ${ }^{14}$ Larkum et al. (1999b).

current for these spikes to NMDA receptor channels and distinguishes them from local $\mathrm{Ca}^{2+}$ electrogenesis via voltage-gated $\mathrm{Ca}^{2+}$ channels. However, in L6 neurons, EPSC-like current injection into the distal apical dendrite (Fig. 6) did not lead to the kind of broad responses we observed with extracellular stimulation (Fig. 10). Therefore, there was not the same ambiguity as in L5 neurons about the nature of the resulting AP-5-sensitive regenerative event caused by synaptic stimulation. Moreover, we tested further for the possibility of a synaptically evoked calcium spike under AP-5 with stimulation far above threshold and observed more depolarization but without the increase in duration seen under control conditions.

Broadly speaking, the active properties of L6 pyramidal neuron dendrites appear to lie in a continuum between the powerful $\mathrm{Ca}^{2+}$ electrogenesis of L5 apical dendrites (Amitai et al., 1993; Schiller et al., 1997; Rhodes et al., 1999; Larkum et al., 2009) and the rather weaker influence of dendritic $\mathrm{Ca}^{2+}$ channels in L2/3 pyramidal neurons (Svoboda et al., 1997; Rhodes et al., 2002; Waters et al., 2003; Larkum et al., 2007). Dendritic spikes are readily elicited in the apical dendrites of all three pyramidal neuron types by EPSC waveforms. In L6 pyramidal neurons, EPSC waveform current injection farther than $300 \mu \mathrm{m}$ away from the soma led to multiple dendritically initiated spike components, which eventually drove the cell body to fire. However, long stepwise current injection into the apical dendrite only weakly increased the variability of output APs at the soma. In contrast, long current injection in L5 pyramidal neurons robustly leads to dendritic plateau potentials and burst firing of the neuron (Williams and Stuart, 1999; Larkum et al., 2001; Larkum and Zhu, 2002). In L2/3 neurons, in contrast, steady-state dendritic current injection has no influence on the somatic interspike interval variability (Larkum et al., 2007). Therefore, both L5 and L6 pyramidal neurons share the property that the dendritic and axonal AP initiation zones can bidirectionally interact with each other, although the interaction appears to be weaker in L6 pyramidal neurons. This may be due to a difference in the densities of voltage-gated channels in the dendritic initiation zones of both neurons and/or a difference in the propagation of signals along the apical dendrite. In this respect, conditions in vivo, where resting $V_{\mathrm{m}}$ of $\mathrm{L} 6$ neurons will be under the influence of several factors, including synaptic activity (Waters and Helmchen, 2004), may also alter the interplay between the two initiation zones.

\section{Dendritic inhibition}

As in other cortical pyramidal neurons, we found that dendritic inhibition is effective in blocking dendritic $\mathrm{Ca}^{2+}$ electrogenesis in L6 pyramidal neurons (Buzsáki et al., 1996; Miles et al., 1996; PérezGarci et al., 2006; Larkum et al., 2007; Murayama et al., 2009). The dendritic inhibition acted via both $\mathrm{GABA}_{\mathrm{A}}$ and $\mathrm{GABA}_{\mathrm{B}}$ receptors and was effective over the same time scales as in L5 and L2/3 pyramidal neurons ( $150 \mathrm{~ms}$ via $\mathrm{GABA}_{\mathrm{A}}$ receptors and up to $400 \mathrm{~ms}$ via $\mathrm{GABA}_{\mathrm{B}}$ receptors) (Pérez-Garci et al., 2006; Larkum et al., 2007). The placement of the extracellular electrode for the recruitment of dendritic inhibition used in this study (upper L5/lower L4) was chosen to be analogous to the stimulation in or near L1 used for inhibiting the apical dendrites of L5 and L2/3 neurons. This location would also correspond most closely to the influence of thalamocortical input on inhibition in L4 (Douglas and Martin, 1991; Porter et al., 2001; Swadlow et al., 2002; Gabernet et al., 2005; Cruikshank et al., 2007). Since inhibitory neurons in L4 tend to act locally (Schubert et al., 2003), the resultant inhibition is likely to have influenced and predominantly targeted the apical dendrites of L6 pyramidal neurons, as was demonstrated for L5 (Pérez-Garci et al., 2006). Thalamocortical inputs to L4 would therefore be expected to influence the integrative process in the distal apical dendrites of L6 pyramidal neurons by providing powerful and long-lasting disynaptic inhibition.

\section{Implications for L6 pyramidal neurons in the neocortical circuit}

A recent study showed that the first-order thalamic relay, which provides numerous terminations in L4 (Sorkin et al., 1998; Gil et al., 1999; Sherman and Guillery, 2002; Bruno and Sakmann, 2006), in fact contacts L6 pyramidal neurons predominantly on 
a

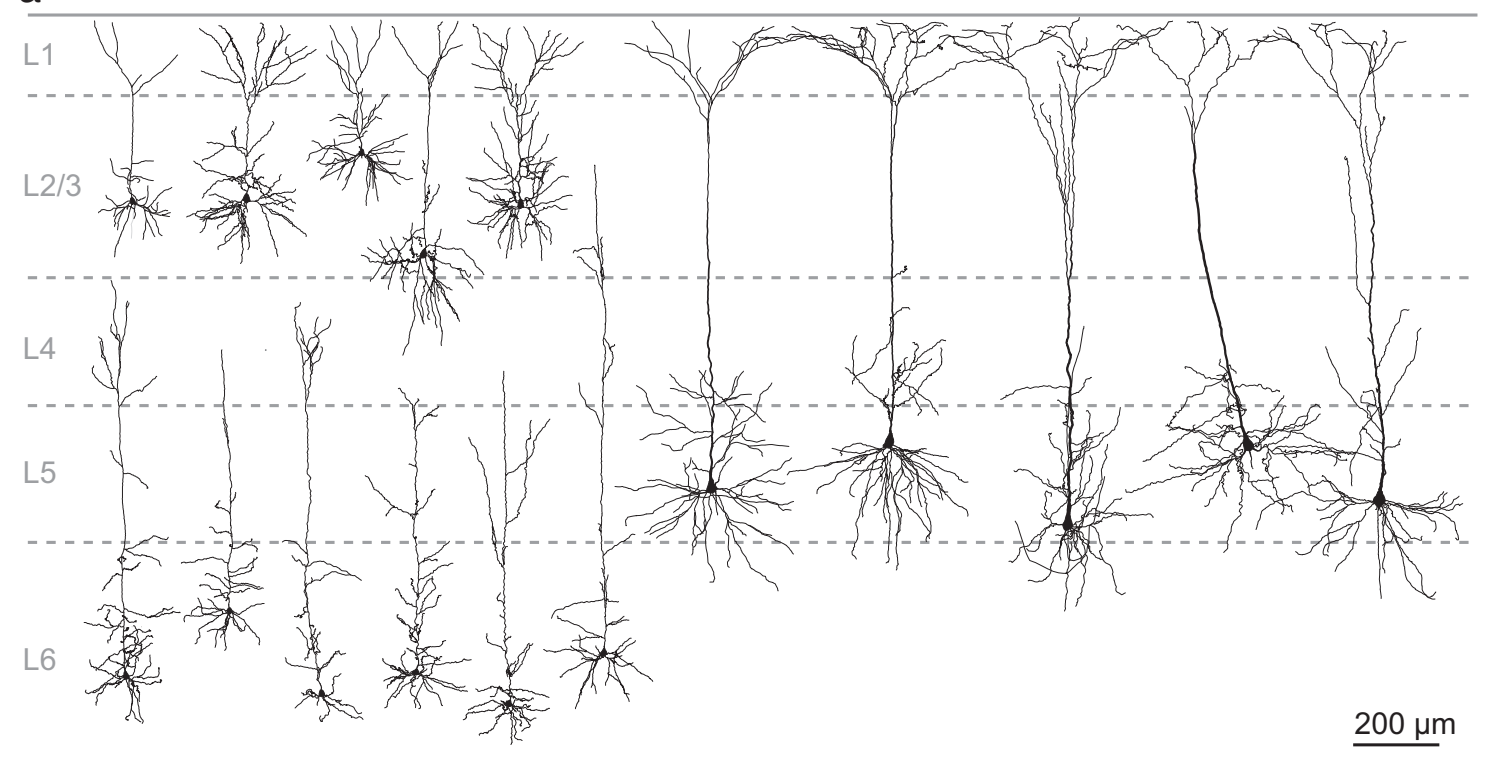

b

\begin{tabular}{llll}
\hline Pyramidal cell type & Layer $\mathbf{6}$ & Layer 2/3 & Layer 5 \\
\hline Average length apical tree $(\mu \mathrm{m})$ & $963 \pm 160$ & $482 \pm 37$ & $1341 \pm 154$ \\
\hline Average diameter apical tree $(\mu \mathrm{m})$ & $1.33 \pm 0.22$ & $1.57 \pm 0.46$ & $3.35 \pm 0.61$ \\
Average length apical shaft $(\mu \mathrm{m})$ & $772 \pm 111$ & $323 \pm 244$ & $739 \pm 186$ \\
Average diameter apical shaft $(\mu \mathrm{m})$ & $1.49 \pm 0.33$ & $2.11 \pm 1.02$ & $4.94 \pm 1.10$ \\
Effective length constant soma $\rightarrow$ dend (shaft) & 501 & $556 \dagger$ & $438 \ddagger$ \\
Effective electrotonic length soma $\rightarrow$ dend (shaft) & 1.54 & 0.58 & 1.69 \\
Effective length constant dend (shaft) $\rightarrow$ soma & 334 & $302 \dagger$ & $457 \ddagger$ \\
\hline Effective electrotonic length dend $($ shaft) $\rightarrow$ soma & 2.31 & 1.07 & 1.62 \\
\hline
\end{tabular}

Figure 12. Anatomical comparison of apical dendrites of different pyramidal neurons in the neocortex. $\boldsymbol{a}$, Neurolucida reconstructions of pyramidal neurons from layers $2 / 3,5$, and 6 of the somatosensory cortex in rats. $L 6$ cells were reconstructed from cells used in this study. The L2/3 cells were taken from our unpublished recordings and the $L 5$ cells are those used in the figures of Larkum et al., (2001) for which dendritic and somatic recordings were published (used with permission). $\boldsymbol{b}$, Table showing the average data for five neurons from L2/3, L5, and L6 neurons from L6 shown in $\boldsymbol{a}$. Measurements were made for the entire length of the apical tree, i.e., the path from the cell body to the dendritic endpoint furthest from the cell body and also for the apical shaft, i.e., the path from the cell body to the main bifurcation point on the apical dendrite. The terms "effective length constant" and "effective electrotonic length" refer to $\lambda_{\text {eff }}$ as defined in the main text and the analogous concept of $L_{\text {eff }}=/ / \lambda_{\text {eff }}$ (where/is the physical length). These are empirically derived distances for the attenuation of steady-state signals traveling along the apical dendrite and should not be confused with the $\lambda$ and $L$ used for modeling. They are used here for comparison between cell types. $t$, from Larkum et al. (2007); $\neq$, from Williams (2004); used with permission.

their basal dendrites in L6 (da Costa and Martin, 2009). This highlights the need for close investigation of all connectivity with regard to which part of the dendritic tree is contacted. Moreover, disynaptic connections make the functional connectivity even more complicated. For example, first-order thalamic input could be relayed to the apical dendrites of L6 pyramidal cells via spiny stellate or smooth cells in L4 (Gibson et al., 1999; Cruikshank et al., 2007). A large proportion of input to L6 neurons is predicted to be from local recurrent circuitry (McGuire et al., 1984; Zhang and Deschènes, 1997; Binzegger et al., 2004; Mercer et al., 2005; West et al., 2006; Douglas and Martin, 2007). Of this recurrent connectivity, one component of input to the L6 apical dendrites could come from corticothalamic L6 neurons themselves (McGuire et al., 1984; Zhang and Deschènes, 1997). We have shown here that the electrogenic properties of the apical dendrite can affect output spiking patterns and allow L6 pyramidal neurons to associate L6 and L4 input. This, combined with the unique location of both the distal apical and basal dendrites is therefore crucial for understanding corticocortical and thalamocortical interactions.

\section{References}

Alitto HJ, Usrey WM (2003) Corticothalamic feedback and sensory processing. Curr Opin Neurobiol 13:440-445.

Amitai Y, Friedman A, Connors BW, Gutnick MJ (1993) Regenerative activity in apical dendrites of pyramidal cells in neocortex. Cereb Cortex 3:26-38.

Archie KA, Mel BW (2000) A model for intradendritic computation of binocular disparity. Nat Neurosci 3:54-63.

Barth AM, Vizi ES, Zelles T, Lendvai B (2008) Alpha2-adrenergic receptors modify dendritic spike generation via HCN channels in the prefrontal cortex. J Neurophysiol 99:394-401.

Bathellier B, Margrie TW, Larkum ME (2009) Properties of piriform cortex pyramidal cell dendrites: implications for olfactory circuit design. J Neurosci 29:12641-12652.

Bekkers JM (2000) Distribution and activation of voltage-gated potassium channels in cell-attached and outside-out patches from large layer 5 cortical pyramidal neurons of the rat. J Physiol 525:611-620.

Berger T, Larkum ME, Lüscher HR (2001) High I-h channel density in the distal apical dendrite of layer $\mathrm{V}$ pyramidal cells increases bidirectional attenuation of EPSPs. J Neurophysiol 85:855-868.

Binzegger T, Douglas RJ, Martin KA (2004) A quantitative map of the circuit of cat primary visual cortex. J Neurosci 24:8441-8453. 
Bourassa J, Pinault D, Deschênes M (1995) Corticothalamic projections from the cortical barrel field to the somatosensory thalamus in rats: a single-fibre study using biocytin as an anterograde tracer. Eur J Neurosci 7:19-30.

Brumberg JC, Hamzei-Sichani F, Yuste R (2003) Morphological and physiological characterization of layer VI corticofugal neurons of mouse primary visual cortex. J Neurophysiol 89:2854-2867.

Bruno RM, Sakmann B (2006) Cortex is driven by weak but synchronously active thalamocortical synapses. Science 312:1622-1627.

Bruno RM, Simons DJ (2002) Feedforward mechanisms of excitatory and inhibitory cortical receptive fields. J Neurosci 22:10966-10975.

Buzsáki G, Penttonen M, Nádasdy Z, Bragin A (1996) Pattern and inhibition-dependent invasion of pyramidal cell dendrites by fast spikes in the hippocampus in vivo. Proc Natl Acad Sci U S A 93:9921-9925.

Chmielowska J, Carvell GE, Simons DJ (1989) Spatial organization of thalamocortical and corticothalamic projection systems in the rat SmI barrel cortex. J Comp Neurol 285:325-338.

Connors BW, Gutnick MJ (1990) Intrinsic firing patterns of diverse neocortical neurons. Trends Neurosci 13:99-104.

Connors BW, Gutnick MJ, Prince DA (1982) Electrophysiological properties of neocortical neurons in vitro. J Neurophysiol 48:1302-1320.

Cruikshank SJ, Lewis TJ, Connors BW (2007) Synaptic basis for intense thalamocortical activation of feedforward inhibitory cells in neocortex. Nat Neurosci 10:462-468.

Cruikshank SJ, Urabe H, Nurmikko AV, Connors BW (2010) Pathwayspecific feedforward circuits between thalamus and neocortex revealed by selective optical stimulation of axons. Neuron 65:230-245.

da Costa NM, Martin KA (2009) Selective targeting of the dendrites of corticothalamic cells by thalamic afferents in area 17 of the cat. J Neurosci 29:13919-13928.

Deschênes M, Veinante P, Zhang ZW (1998) The organization of corticothalamic projections: reciprocity versus parity. Brain Res Brain Res Rev 28:286-308.

Diamond ME (1995) Somatosensory thalamus of the rat. In: Cerebral cortex: Vol 11, The barrel cortex of rodents (Diamond ME, Jones EG, eds), pp 189-220. New York: Plenum.

Douglas RJ, Martin KA (1991) A functional microcircuit for cat visual cortex. J Physiol 440:735-769.

Douglas RJ, Martin KA (2007) Recurrent neuronal circuits in the neocortex. Curr Biol 17:R496-R500.

Eccles JC (1992) Evolution of consciousness. Proc Natl Acad Sci U S A 89:7320-7324.

Felleman DJ, Van Essen DC (1991) Distributed hierarchical processing in the primate cerebral cortex. Cereb Cortex 1:1-47.

Ferrer I, Fabregues I, Condom E (1986) A Golgi study of the sixth layer of the cerebral cortex. I. The lissencephalic brain of Rodentia, Lagomorpha, Insectivora and Chiroptera. J Anat 145:217-234.

Froemke RC, Dan Y (2002) Spike-timing-dependent synaptic modification induced by natural spike trains. Nature 416:433-438.

Gabernet L, Jadhav SP, Feldman DE, Carandini M, Scanziani M (2005) Somatosensory integration controlled by dynamic thalamocortical feedforward inhibition. Neuron 48:315-327.

Gasparini S, Migliore M, Magee JC (2004) On the initiation and propagation of dendritic spikes in CA1 pyramidal neurons. J Neurosci 24:11046-11056.

Gibson JR, Beierlein M, Connors BW (1999) Two networks of electrically coupled inhibitory neurons in neocortex. Nature 402:75-79.

Gil Z, Connors BW, Amitai Y (1999) Efficacy of thalamocortical and intracortical synaptic connections: quanta, innervation, and reliability. Neuron 23:385-397.

Golding NL, Spruston N (1998) Dendritic sodium spikes are variable triggers of axonal action potentials in hippocampal CA1 pyramidal neurons. Neuron 21:1189-1200.

Golding NL, Staff NP, Spruston N (2002) Dendritic spikes as a mechanism for cooperative long-term potentiation. Nature 418:326-331.

Gulledge AT, Stuart GJ (2003) Excitatory actions of GABA in the cortex. Neuron 37:299-309.

Häusser M, Spruston N, Stuart GJ (2000) Diversity and dynamics of dendritic signaling. Science 290:739-744.

Häusser M, Major G, Stuart GJ (2001) Differential shunting of EPSPs by action potentials. Science 291:138-141.

Hoffman DA, Magee JC, Colbert CM, Johnston D (1997) K+ channel reg- ulation of signal propagation in dendrites of hippocampal pyramidal neurons. Nature 387:869-875.

Johnston D, Magee JC, Colbert CM, Christie BR (1996) Active properties of neuronal dendrites. Annu Rev Neurosci 19:165-186.

Johnston D, Hoffman DA, Magee JC, Poolos NP, Watanabe S, Colbert CM, Migliore M (2000) Dendritic potassium channels in hippocampal pyramidal neurons. J Physiol 525:75-81.

Jung HY, Mickus T, Spruston N (1997) Prolonged sodium channel inactivation contributes to dendritic action potential attenuation in hippocampal pyramidal neurons. J Neurosci 17:6639-6646.

Kim HG, Connors BW (1993) Apical dendrites of the neocortex: correlation between sodium- and calcium-dependent spiking and pyramidal cell morphology. J Neurosci 13:5301-5311.

Korngreen A, Sakmann B (2000) Voltage-gated K+ channels in layer 5 neocortical pyramidal neurones from young rats: subtypes and gradients. J Physiol 525:621-639.

Kumar P, Ohana O (2008) Inter- and intralaminar subcircuits of excitatory and inhibitory neurons in layer $6 \mathrm{a}$ of the rat barrel cortex. J Neurophysiol 100:1909-1922.

Larkman A, Mason A (1990) Correlations between morphology and electrophysiology of pyramidal neurons in slices of rat visual cortex. I. Establishment of cell classes. J Neurosci 10:1407-1414.

Larkum ME, Zhu JJ (2002) Signaling of layer 1 and whisker-evoked Ca2+ and $\mathrm{Na}+$ action potentials in distal and terminal dendrites of rat neocortical pyramidal neurons in vitro and in vivo. J Neurosci 22:6991-7005.

Larkum ME, Kaiser KM, Sakmann B (1999a) Calcium electrogenesis in distal apical dendrites of layer 5 pyramidal cells at a critical frequency of back-propagating action potentials. Proc Natl Acad Sci U S A 96:14600-14604.

Larkum ME, Zhu JJ, Sakmann B (1999b) A new cellular mechanism for coupling inputs arriving at different cortical layers. Nature 398:338-341.

Larkum ME, Zhu JJ, Sakmann B (2001) Dendritic mechanisms underlying the coupling of the dendritic with the axonal action potential initiation zone of adult rat layer 5 pyramidal neurons. J Physiol 533:447-466.

Larkum ME, Waters J, Sakmann B, Helmchen F (2007) Dendritic spikes in apical dendrites of neocortical layer $2 / 3$ pyramidal neurons. J Neurosci 27:8999-9008.

Larkum ME, Watanabe S, Lasser-Ross N, Rhodes P, Ross WN (2008) Dendritic properties of turtle pyramidal neurons. J Neurophysiol 99:683-694.

Larkum ME, Nevian T, Sandler M, Polsky A, Schiller J (2009) Synaptic integration in tuft dendrites of layer 5 pyramidal neurons: a new unifying principle. Science 325:756-760.

Letzkus JJ, Kampa BM, Stuart GJ (2005) A distance-dependent switch in the time window for induction of spike-timing-dependent synaptic plasticity. Soc Neurosci Abstr 31:384.13.

Llinás RR, Ribary U (2001) Consciousness and the brain: the thalamocortical dialogue in health and disease. Ann N Y Acad Sci 929:166-175.

London M, Häusser M (2005) Dendritic computation. Annu Rev Neurosci 28:503-532.

Markram H, Helm PJ, Sakmann B (1995) Dendritic calcium transients evoked by single back-propagating action potentials in rat neocortical pyramidal neurons. J Physiol 485:1-20.

Mason A, Larkman A (1990) Correlations between morphology and electrophysiology of pyramidal neurons in slices of rat visual cortex. II. Electrophysiology. J Neurosci 10:1415-1428.

McGuire BA, Hornung JP, Gilbert CD, Wiesel TN (1984) Patterns of synaptic input to layer 4 of cat striate cortex. J Neurosci 4:3021-3033.

Mel BW (1993) Synaptic integration in an excitable dendritic tree. J Neurophysiol 70:1086-1101.

Mercer A, West DC, Morris OT, Kirchhecker S, Kerkhoff JE, Thomson AM (2005) Excitatory connections made by presynaptic cortico-cortical pyramidal cells in layer 6 of the neocortex. Cereb Cortex 15:1485-1496.

Miles R, Tóth K, Gulyás AI, Hájos N, Freund TF (1996) Differences between somatic and dendritic inhibition in the hippocampus. Neuron 16:815-823.

Murayama M, Pérez-Garci E, Nevian T, Bock T, Senn W, Larkum ME (2009) Dendritic encoding of sensory stimuli controlled by deep cortical interneurons. Nature 457:1137-1141.

Nevian T, Sakmann B (2004) Single spine Ca2 + signals evoked by coincident EPSPs and backpropagating action potentials in spiny stellate cells of layer 4 in the juvenile rat somatosensory barrel cortex. J Neurosci 24:1689-1699. 
Nevian T, Larkum ME, Polsky A, Schiller J (2007) Properties of basal dendrites of layer 5 pyramidal neurons: a direct patch-clamp recording study. Nat Neurosci 10:206-214.

Pérez-Garci E, Gassmann M, Bettler B, Larkum ME (2006) The GABAB1b isoform mediates long-lasting inhibition of dendritic $\mathrm{Ca} 2+$ spikes in layer 5 somatosensory pyramidal neurons. Neuron 50:603-616.

Pike FG, Meredith RM, Olding AW, Paulsen O (1999) Rapid report: postsynaptic bursting is essential for 'Hebbian' induction of associative long-term potentiation at excitatory synapses in rat hippocampus. J Physiol 518:571-576.

Porter JT, Johnson CK, Agmon A (2001) Diverse types of interneurons generate thalamus-evoked feedforward inhibition in the mouse barrel cortex. J Neurosci 21:2699-2710.

Reichova I, Sherman SM (2004) Somatosensory corticothalamic projections: distinguishing drivers from modulators. J Neurophysiol 92:21852197.

Rhodes PA (1999) Functional implications of active currents in the dendrites of pyramidal neurons. In: Cerebral cortex: Vol. 13, Models of cortical circuits (Ulinski PS, Jones EG, Peters A, eds), pp 139-200. New York: Plenum.

Rhodes PA, Larkum ME, Waters J, Helmchen F, Llinás R, Sakmann B (2002) Simulations of layer $2 / 3$ pyramidal cells suggest they are not readily driven by layer 1 input. Soc Neurosci Abstr 28:345.311.

Schaefer AT, Helmstaedter M, Schmitt AC, Bar-Yehuda D, Almog M, BenPorat H, Sakmann B, Korngreen A (2007) Dendritic voltage-gated K+ conductance gradient in pyramidal neurones of neocortical layer $5 \mathrm{~B}$ from rats. J Physiol 579:737-752.

Schiller J, Schiller Y, Stuart G, Sakmann B (1997) Calcium action potentials restricted to distal apical dendrites of rat neocortical pyramidal neurons. J Physiol 505:605-616.

Schiller J, Major G, Koester HJ, Schiller Y (2000) NMDA spikes in basal dendrites of cortical pyramidal neurons. Nature 404:285-289.

Schubert D, Kötter R, Zilles K, Luhmann HJ, Staiger JF (2003) Cell typespecific circuits of cortical layer IV spiny neurons. J Neurosci 23:29612970.

Sherman SM, Guillery RW (2002) The role of the thalamus in the flow of information to the cortex. Philos Trans R Soc Lond B Biol Sci 357:1695-1708.

Shlosberg D, Amitai Y, Azouz R (2006) Time-dependent, layer-specific modulation of sensory responses mediated by neocortical layer 1. J Neurophysiol 96:3170-3182.

Siegel M, Körding KP, König P (2000) Integrating top-down and bottom-up sensory processing by somato-dendritic interactions. J Comput Neurosci 8:161-173.

Sjöström PJ, Häusser M (2006) A cooperative switch determines the sign of synaptic plasticity in distal dendrites of neocortical pyramidal neurons. Neuron 51:227-238.

Sorkin LS, Puig S, Jones DL (1998) Spinal bicuculline produces hypersensitivity of dorsal horn neurons: effects of excitatory amino acid antagonists. Pain 77:181-190.
Spruston N (2008) Pyramidal neurons: dendritic structure and synaptic integration. Nat Rev Neurosci 9:206-221.

Spruston N, Schiller Y, Stuart G, Sakmann B (1995) Activity-dependent action-potential invasion and calcium influx into hippocampal CA1 dendrites. Science 268:297-300.

Stuart G, Spruston N (1998) Determinants of voltage attenuation in neocortical pyramidal neuron dendrites. J Neurosci 18:3501-3510.

Stuart G, Schiller J, Sakmann B (1997) Action potential initiation and propagation in rat neocortical pyramidal neurons. J Physiol 505:617-632.

Stuart GJ, Häusser M (2001) Dendritic coincidence detection of EPSPs and action potentials. Nat Neurosci 4:63-71.

Stuart GJ, Sakmann B (1994) Active propagation of somatic actionpotentials into neocortical pyramidal cell dendrites. Nature 367:69-72.

Svoboda K, Denk W, Kleinfeld D, Tank DW (1997) In vivo dendritic calcium dynamics in neocortical pyramidal neurons. Nature 385:161-165.

Svoboda K, Helmchen F, Denk W, Tank DW (1999) Spread of dendritic excitation in layer $2 / 3$ pyramidal neurons in rat barrel cortex in vivo. Nat Neurosci 2:65-73.

Swadlow HA (2002) Thalamocortical control of feed-forward inhibition in awake somatosensory 'barrel' cortex. Philos Trans R soc Lond B Biol Sci 357:1717-1727.

Swadlow HA, Gusev AG, Bezdudnaya T (2002) Activation of a cortical column by a thalamocortical impulse. J Neurosci 22:7766-7773.

Vetter P, Roth A, Häusser M (2001) Propagation of action potentials in dendrites depends on dendritic morphology. J Neurophysiol 85:926-937.

Waters J, Helmchen F (2004) Boosting of action potential backpropagation by neocortical network activity in vivo. J Neurosci 24:11127-11136.

Waters J, Helmchen F (2006) Background synaptic activity is sparse in neocortex. J Neurosci 26:8267-8277.

Waters J, Larkum M, Sakmann B, Helmchen F (2003) Supralinear Ca2+ influx into dendritic tufts of layer $2 / 3$ neocortical pyramidal neurons in vitro and in vivo. J Neurosci 23:8558-8567.

West DC, Mercer A, Kirchhecker S, Morris OT, Thomson AM (2006) Layer 6 cortico-thalamic pyramidal cells preferentially innervate interneurons and generate facilitating EPSPs. Cereb Cortex 16:200-211.

Williams SR (2004) Spatial compartmentalization and functional impact of conductance in pyramidal neurons. Nat Neurosci 7:961-967.

Williams SR, Stuart GJ (1999) Mechanisms and consequences of action potential burst firing in rat neocortical pyramidal neurons. J Physiol 521:467-482.

Zhang ZW, Deschênes M (1997) Intracortical axonal projections of lamina VI cells of the primary somatosensory cortex in the rat: a single-cell labeling study. J Neurosci 17:6365-6379.

Zhang ZW, Deschênes M (1998) Projections to layer VI of the posteromedial barrel field in the rat: a reappraisal of the role of corticothalamic pathways. Cereb Cortex 8:428-436.

Zhu JJ (2000) Maturation of layer 5 neocortical pyramidal neurons: amplifying salient layer 1 and layer 4 inputs by $\mathrm{Ca} 2+$ action potentials in adult rat tuft dendrites. J Physiol 526:571-587. 